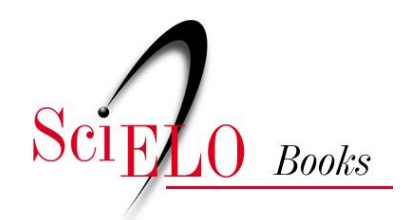

กิ FIOCRUZ

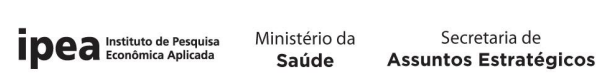

\title{
Análise do subsistema de serviços em saúde na dinâmica do complexo econômico-industrial da saúde
}

\author{
Laís Silveira Costa \\ Carlos A. Grabois Gadelha \\ José Maldonado \\ Marco Vargas \\ Cristiane Quental
}

\section{SciELO Books / SciELO Livros / SciELO Libros}

COSTA, LS., et al. Análise do subsistema de serviços em saúde na dinâmica do complexo econômico-industrial da saúde. In FUNDAÇÃO OSWALDO CRUZ. A saúde no Brasil em 2030 prospecção estratégica do sistema de saúde brasileiro: desenvolvimento produtivo e complexo da saúde [online]. Rio de Janeiro: Fiocruz/Ipea/Ministério da Saúde/Secretaria de Assuntos Estratégicos da Presidência da República, 2013. Vol. 5. pp. 121-159. ISBN 978-85-8110-019-7. Available from SciELO Books <http://books.scielo.org>.

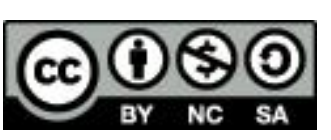

All the contents of this chapter, except where otherwise noted, is licensed under a Creative Commons Attribution-Non Commercial-ShareAlike 3.0 Unported.

Todo o conteúdo deste capítulo, exceto quando houver ressalva, é publicado sob a licença Creative Commons Atribuição Uso Não Comercial - Partilha nos Mesmos Termos 3.0 Não adaptada.

Todo el contenido de este capítulo, excepto donde se indique lo contrario, está bajo licencia de la licencia Creative Commons Reconocimento-NoComercial-CompartirIgual 3.0 Unported. 
Análise do Subsistema de Serviços em Saúde na Dinâmica do

Complexo Econômico-Industrial da Saúde 


\title{
ANÁLISE DO SUBSISTEMA DE SERVIÇOS EM SAÚDE NA DINÂMICA DO COMPLEXO ECONÔMICO-INDUSTRIAL DA SAÚDE ${ }^{1}$
}

\author{
Laís Silveira Costa \\ Carlos A. Grabois Gadelha \\ José Maldonado \\ Marco Vargas \\ Cristiane Quental
}

\section{1 | INTRODUÇÃO}

A dinâmica entre os segmentos produtivos e os serviços relacionados à prestação de cuidados à saúde implica uma relação sistêmica entre determinados setores industriais e serviços sociais, caracterizando o que atualmente é conhecido como complexo produtivo da saúde² (GADELHA, 2003). No âmbito deste complexo, o segmento de serviços é aquele de maior peso econômico. Sua importância é enfatizada tanto pelo seu papel no Sistema Nacional de Inovação em Saúde quanto por ser responsável pela demanda dos produtos dos demais segmentos do complexo produtivo da saúde e por parcela significativa de renda e emprego nacionais e do setor terciário especializado.

Além da importância dos serviços na geração de inovações organizacionais, a interface entre estes serviços e os segmentos industriais do CEIS é reconhecida também por Albuquerque e Cassiolato (2000), que ademais enfatizam o papel de mediador do sistema de assistência médica nas interações ocorridas no bojo do CEIS, tanto com as universidades, como com as instituições de pesquisas e as indústrias.

O subsistema de serviços em saúde exerce particular função na dinamização da relação entre os subsistemas diversos, estabelecendo o caráter sistêmico do Complexo Econômico-Industrial da Saúde (CEIS), em especial pela sua

1 Os autores agradecem a colaboração dos demais pesquisadores do Grupo de Inovação em Saúde da Fiocruz, em especial de Taís Borges e Paula Burd, pelos seus inestimáveis comentários e contribuição na sistematização final deste artigo.

2 Neste texto as terminologias "Complexo Produtivo da Saúde", "Complexo da Saúde", "Complexo Produtivo" e "Complexo" serão utilizadas indiscriminadamente para designar "Complexo Econômico-Industrial da Saúde" ou seu acrônimo "CEIS". 
função de consumidor e demandante, muitas vezes influenciando e sendo influenciado pela produção de equipamentos médico-hospitalares, produtos farmacêuticos, imunoderivados, soros e demais insumos.

Como consequência, diferenciações na orientação dos serviços em saúde e na própria estrutura produtiva do CEIS normalmente levam a adaptações nos componentes dos sistemas nacionais de saúde, situando a relevância da adequação do arcabouço institucional e do tratamento sistêmico dos setores que compõem o complexo da saúde.

Note-se que não é trivial acomodar os interesses públicos e privados situados nesta agenda, não somente por sua importância social e econômica como também por seu caráter estratégico, dado que os serviços em saúde articulam uma gama de tecnologias portadoras de futuro (por serem centrais à economia do conhecimento) (COSTA et al., 2012).

A assimetria na força dos interesses sanitários e econômicos envolvidos tem sido responsável, no Brasil, pelo estabelecimento de uma relação hierárquica entre eles, favorável aos últimos ${ }^{3}$. Em decorrência, sistemas de saúde vêm incorporando tecnologias que, em sua maioria, não são as mais adequadas às características epidemiológicas e demográficas e nem aos modelos institucionais da política sanitária dos países (MEDICAL DEVICES, 2010).

O conjunto destas variáveis tem ocasionado um crescimento insustentável dos gastos com a prestação de serviços em saúde. A necessidade de redução destes custos tem levado a movimentos sucessivos de tentativa de reformar os sistemas de saúde, tanto no mundo quanto no Brasil. Visando contemplar a crescente participação de doenças crônicas e decorrentes do estilo de vida no conjunto das doenças observadas, tem se buscado a integração dos serviços prestados no âmbito dos sistemas de saúde, assim como o deslocamento da sua porta de entrada para a atenção primária. Atualmente uma parcela relevante da população ainda prioriza o hospital como contato inicial no sistema, gerando ineficiências diversas (consideradas as restrições de recursos disponíveis).

Além disto, observa-se um movimento de reestruturação deste sistema, favorecido pela incorporação do uso da tecnologia de informação e comunicação (TIC) na saúde, com resultados expressivos para a efetividade dos sistemas de saúde, sobretudo quanto ao acesso e à redução de custos. É o caso da telemedicina, diagnósticos remotos e cirurgias ambulatoriais, assim como de novos modelos de prestação (como

3 Dentre os atores envolvidos nesta arena decisória, vale citar, a título de ilustração, o Estado, as instituições públicas e privadas prestadoras de serviços, as indústrias do complexo da saúde e, mais recentemente, as empresas financeiras (Vianna, 1994). Ressalte-se assim que essa assimetria de poder é multifacetada, existindo tanto dentro dos interesses sanitários (entre os serviços públicos, filantrópicos e privados) quanto dentro dos econômicos (representados pelos segmentos público, privado nacional e privado internacional). 
os hospitais-dia e a assistência domiciliar). Cabe aqui destacar o papel que os cuidados domiciliares vêm assumindo, criando novas oportunidades de inovação4 ${ }^{4}$ dado que o sistema passa a incorporar diversas novas tecnologias que tornam esse cuidado domiciliar seguro e eficaz.

Assim, é da interação entre setores com objetivos às vezes não consonantes que algumas soluções têm surgido para atender os desafios postos pelas características epidemiológicas e pela necessidade de redução dos crescentes custos com saúde. Podese, desta forma, perceber a força que a arena política exerce sobre a saúde, em especial dada a sua intrínseca relação com o estágio de desenvolvimento de uma dada nação.

Pelas questões expostas, situa-se a importância de analisar a dinâmica do sistema de saúde e a de inovação no âmbito do complexo da saúde brasileiro, ante aos desafios relativos às alterações demográficas e epidemiológicas brasileiras, e os interesses políticos envolvidos.

Para alcançar tal objetivo, propõe-se, neste trabalho, analisar os serviços de saúde sob dois enfoques: tanto como resposta social aos problemas e necessidades da saúde quanto como "um serviço compreendido no interior dos processos de produção, distribuição e consumo, inserido no setor terciário da economia, dependendo de processos que perpassam os espaços do estado e do mercado" (PAIM, 2004, apud VIANA e MACHADO, 2008).

Para tanto, parte-se do olhar da dinâmica global dos serviços em saúde, para depois analisar o sistema de saúde brasileiro, e os desafios pautados pelos interesses públicos e privados que afetam sua arena política decisória. Por fim, é traçado um cenário prospectivo para o segmento de serviços em saúde no Brasil, para o ano de 2030, de modo a subsidiar a adequação do arcabouço político-institucional do complexo da saúde.

\section{2 | DINÂMICA GLOBAL DOS SISTEMAS DE SAÚDE}

Além do perfil sanitário e da estrutura de oferta de cuidados de saúde - questões tradicionalmente associadas à dinâmica desse subsistema —, outros elementos relacionados aos sistemas de saúde influenciam sobremaneira a dinâmica do subsistema de serviços. Entre estes, destacam-se as indústrias do complexo da saúde, as novas tecnologias e a geração de inovação, fator essencial para a competitividade na sociedade contemporânea de conhecimento. Assim, o dinamismo econômico e o potencial de inovação situam os serviços em uma agenda de intenso protagonismo

4 A inovação é tratada aqui como uma descoberta, desenvolvimento ou imitação que leva à adoção de novos produtos, processos produtivos ou sistemas organizacionais (DOSI, 1988). 
na arena política nacional e internacional (ainda que não se aplique o conceito de mercado ao setor de serviços em saúde).

Vários são os interesses em jogo, quando se pensa em estruturar um sistema de saúde, que, de acordo com Lassey et al. (1997, apud IBAÑEZ, 2011), apresenta alguns componentes básicos. O acesso é o grande desafio de qualquer sistema de saúde, afirmam os autores que, ademais, apontam: sua relevância econômica, dado que participam com algo entre 6\% e 15\% do PIB nos países industrializados; a competição acirrada característica do mercado industrial da saúde; o impacto do custo da saúde, indicando a necessidade de reorientar a estrutura dos sistemas e serviços, e de buscar novas tecnologias capazes de aumentar a eficiência da gestão e expandir o acesso, a partir de uma maior eficiência e eficácia do sistema. Ainda segundo os autores, devem ser consideradas: a origem do financiamento, que precisa ser compatível com o modelo institucional do sistema de saúde de cada país; as alterações na configuração da demanda por saúde, um dos maiores desafios hoje, em especial com a transição demográfica; a pressão dos custos e a velocidade em que inovações tecnológicas são inseridas no mercado; e, por fim, a incorporação tecnológica, cujo estágio ainda embrionário da análise sistemática de seus custos e benefícios, bem como as questões éticas que surgem deste processo de incorporação têm colocado importantes desafios à gestão dos sistemas de saúde do mundo.

Dado que os serviços se inserem na estrutura mais ampla dos sistemas de saúde, estes elementos, apontados como estruturantes do sistema, acabam por influenciar também a própria dinâmica dos serviços (VIACAVA et al, 2004). Ressalta-se desta forma a importância da análise destes elementos para se captar as variáveis e interesses diversos envolvidos no subsistema de serviços em saúde.

É razoável entender, por exemplo, que a depender da capacidade e composição do financiamento, do modelo institucional do sistema de saúde, da orientação política quanto ao modelo de desenvolvimento, capacidade de gestão e arcabouço regulatório do Estado, observar-se-ão resultados distintos quanto ao modelo de provisão de serviços em saúde. Isso explica a heterogeneidade dos sistemas de saúde nos diversos países do mundo.

Na realidade, a importância de se entender os componentes básicos de um sistema de saúde para analisar a dinâmica de seus serviços amplifica-se na medida em que, na atualidade, a sustentabilidade dos sistemas está ameaçada.

A expansão dos direitos sociais observada no pós-guerra teve como efeitos colaterais desejáveis uma gama de serviços em saúde crescentemente à disposição da população. Entretanto, na medida em que a expansão do acesso começou a ser acompanhada por uma veloz incorporação tecnológica nos serviços em saúde (em especial a partir das décadas de 1980/1990), observou-se um expressivo aumento do custo referente à prestação desses serviços. 
Este aumento pode ser atribuído tanto ao custo relativo às tecnologias incorporadas pelos sistemas, como ao fato de que elas conseguiram contribuir para o aumento da expectativa de vida da população ${ }^{5}$. Houve, como consequência, um recrudescimento da participação das doenças crônicas no processo saúde-doença que não somente onera sobremaneira os sistemas de saúde, como também demanda gestão e estrutura diferenciadas para a prestação de serviços de atenção à saúde. Este grupo de doenças exige, sobretudo, atenção integrada, envolvendo os diversos níveis de complexidade, extrapolando os serviços de saúde, pois demanda também equipamentos urbanos adequados.

Em decorrência das alterações mencionadas, observa-se no período que o crescimento dos gastos em saúde foram maiores que os do PIB, como se pode depreender a partir de dados apresentados nos Gráficos 1 e 2, apontando não somente o dinamismo do setor, mas também a real vulnerabilidade a que os sistemas estão expostos, dada a limitação dos recursos disponíveis. Este crescimento vem onerando intensa e particularmente os governos, que são os principais financiadores dos sistemas de saúde no mundo, em especial dentre os países mais desenvolvidos onde a prestação de serviços é mais frequentemente universal.

Gráfico 01. Gasto total em Saúde como \% do PIB, 1995 a 2010 (Brasil, média OCDE, média UE e média BRIC)

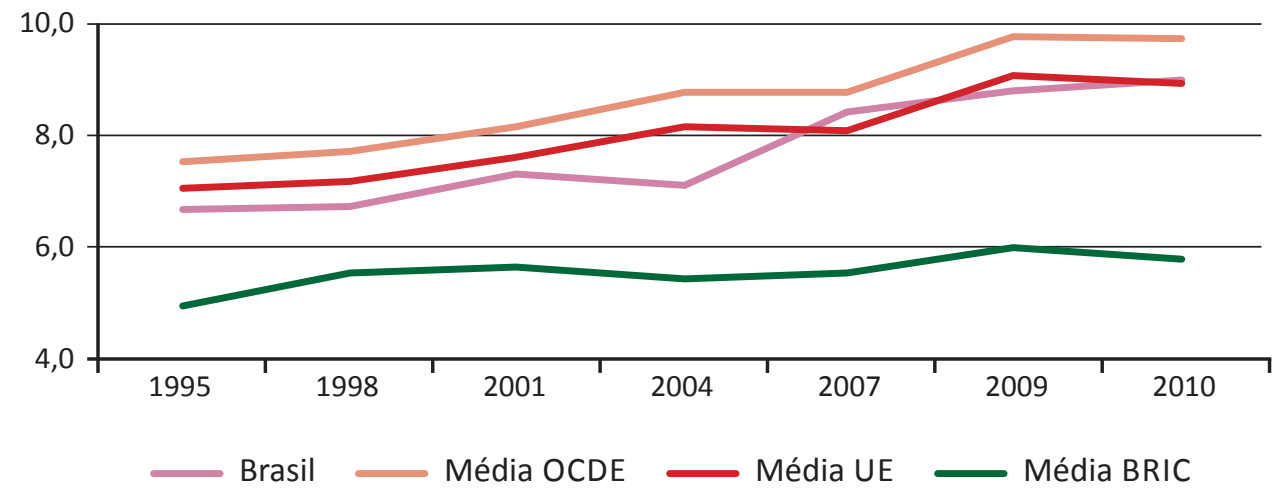

Fonte: Elaborado por GIS/Fiocruz, a partir dos dados da WHO, 2013, acesso fevereiro de 2013.

5 Não se pode atribuir, às tecnologias, responsabilidade exclusiva pelo aumento da expectativa de vida da população mundial. A longevidade também se relaciona com uma série de determinantes sociais da saúde, assim como a expansão de cuidados básicos, antes restrita a uma menor parcela da população. De toda forma, avanços na medicina e na produção do complexo médico-industrial (inovações biomédicas e de materiais) contribuíram sobremaneira para o aumento da expectativa de vida da população mundial. 
Gráfico 02. Evolução dos gastos públicos em Saúde em \% do PIB (países e anos selecionados)

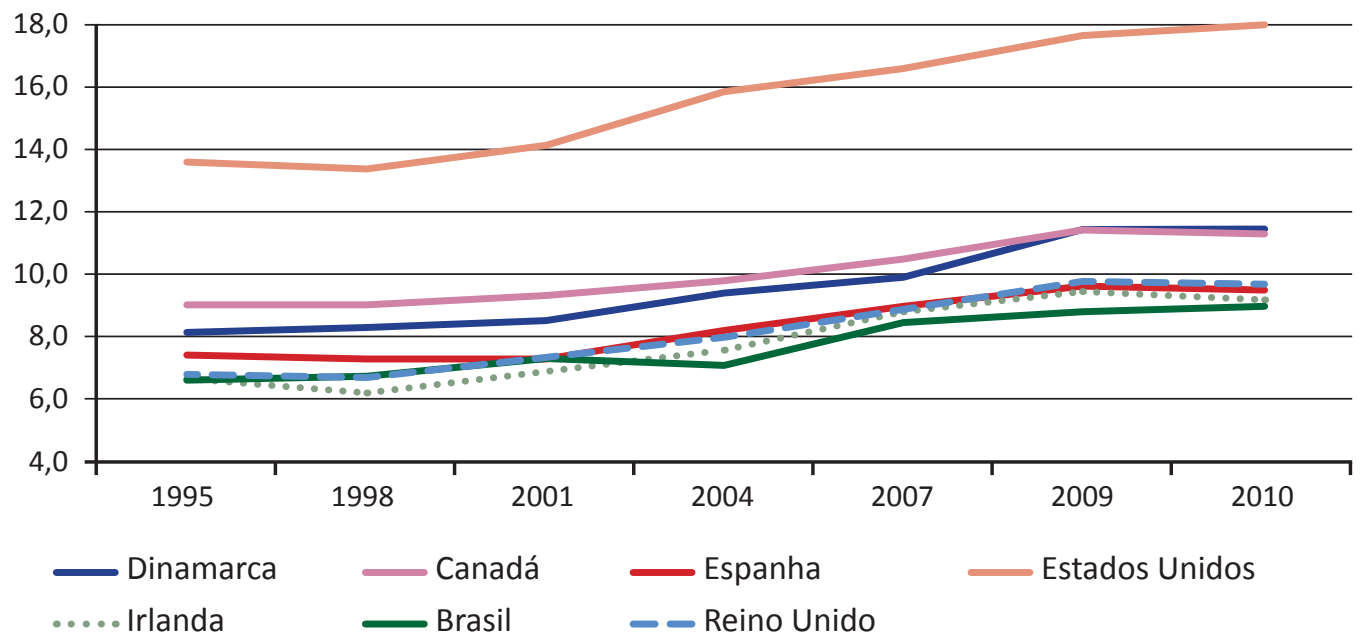

Fonte: Elaborado por GIS/Fiocruz, a partir dos dados da WHO, 2013, acesso fevereiro de 2013.

Assim, a situação hoje vivida pelos gestores dos sistemas de saúde cujos gastos crescem insustentavelmente representa uma equação econômica e política complexa e um grande desafio a ser enfrentado. A vulnerabilidade dos sistemas de saúde torna-se ainda mais evidente ao se verificar que gastos em saúde concentrados no final da vida são majorados substancialmente, em decorrência dos impactos do aumento da longevidade sobre os mesmos, conforme se pode observar no Gráfico 3. Situação esta agravada pela contemporânea transição demográfica (envelhecimento da população acompanhado pela diminuição do número de nascimentos), implicando na diminuição proporcional da população economicamente ativa (BIRD, 2011).

A inadequação do sistema às mudanças epidemiológicas e demográficas, a necessidade de desaceleração dos gastos em saúde, e a insatisfatória relação entre o crescente custo das novas tecnologias e seus benefícios associados ${ }^{6}$ (valendo menção específica à falta de racionalidade na incorporação tecnológica por parte dos sistemas de saúde) são sintomas da crise nos sistemas e modelos de atenção predominantes mundo afora. Estes elementos explicam, ademais, as reformas que se têm tentado empreender nas últimas décadas.

6 Para maiores informações sobre algumas das distorções observadas em decorrência do estagio embrionário da base de conhecimento para nortear a incorporação tecnológica, assim como a sinalização do desequilíbrio de força dos atores envolvidos neste processo, ver Medical Devices (2010). 
Gráfico 03. Evolução da intensidade de uso dos serviços em saúde em função do envelhecimento da população

Intensidade de Uso de Serviço por idade, morte aos 65 anos

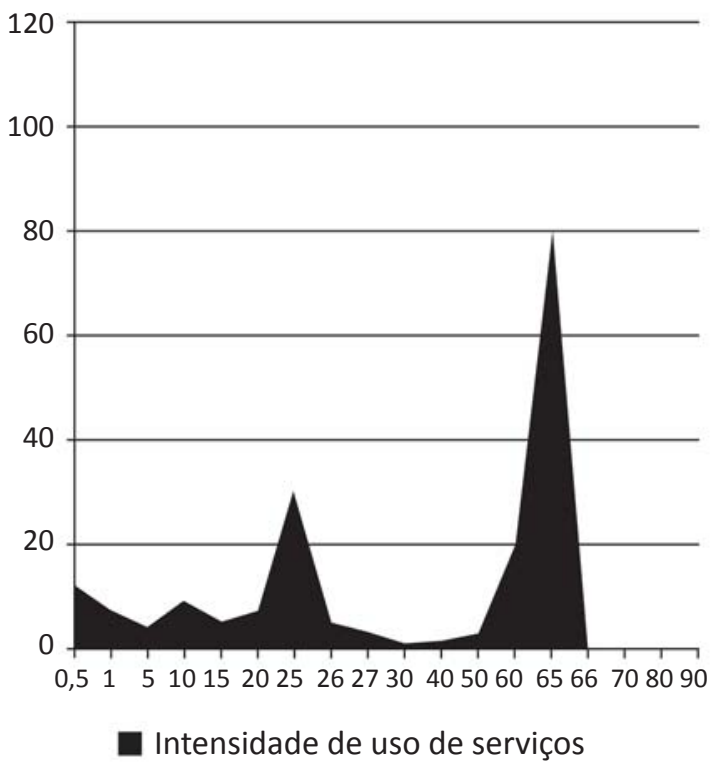

Intensidade de Uso de Serviço por idade, morte aos 90 anos

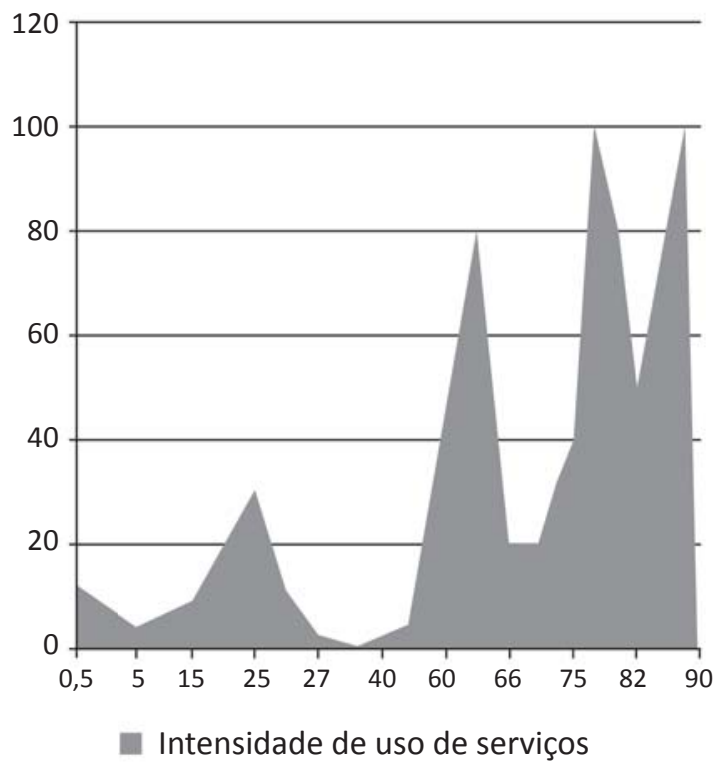

Fonte: Noronha (2011).

Assim, a efetividade dos sistemas de saúde passa pela necessária reestruturação dos mesmos visando a sua adequação às características epidemiológicas da população, que estão cada vez mais marcadas pela incidência de doenças crônicas e mentais e outros determinantes de doenças vinculados a padrões específicos de morbimortalidade (violência, obesidade, tabagismo, urbanização acelerada, para citar os principais). De acordo com Victora et al. (2011), essas alterações nas características de saúde-doença brasileiras são significativas e impactam o perfil das demandas por cuidados de saúde (OLIVEIRA, 2013).

Esta reestruturação encontra seus principais desafios tanto na integração dos serviços como na superação do modelo cuja porta de entrada situa-se no hospital. Em 2003, a Organização Pan-Americana de Saúde (PAHO, 2003) lançou um estudo realçando a necessidade de superar a fragmentação dos serviços, ainda marcante nos sistemas, para tratar de forma eficiente e efetiva as condições crônicas de saúde. 0 estudo alerta ainda que, ao requerer o compartilhamento de informações entre os componentes dos diversos níveis de complexidade da atenção à saúde, o tratamento destas condições exige também a coordenação do financiamento em saúde. Em outras palavras, explicita-se que "integração" passa a ser a palavra de ordem para lidar com os novos desafios epidemiológicos. 
Em relação ao modelo centrado nos hospitais, Mckeee Healy (2000) afirmam que a participação dos mesmos nos gastos globais da atenção é de aproximadamente 50\% dos gastos na prestação dos serviços. Mas, a despeito da pressão pela redução de custos da atenção - sugerindo a necessidade de definir uma porta de entrada de menor complexidade nos serviços de saúde - e da necessidade de integração dos serviços, os hospitais seguem exercendo grande fascínio sobre os usuários, concentrando os saberes mais especializados e desempenhando função central nos sistemas de saúde. Sendo assim, o formato de sua inserção em um novo modelo de atenção integrado também é um tópico que deve ser analisado cuidadosamente. Deste modo, questões como 'qual deve ser o tamanho do hospital', 'como ele deve estar distribuído territorialmente', 'quais deveriam ser suas funções primordiais', entre outras, são particularmente pertinentes nesta transição de estrutura de prestação de serviços.

Estudo realizado por Barbosa (2009) enfatiza justamente este novo perfil de hospital que atualmente está em processo de integração a uma rede diversificada de serviços de saúde. Segundo o autor, este novo modelo de hospital é mais denso tecnologicamente e deverá, cada vez mais, voltar-se para casos que demandam cuidados intensivos. Ressalta, ainda, as

responsabilidades [do hospital] como serviço de retaguarda e de apoio técnico à rede assistencial, como instituição de formação de especialistas $e$ de desenvolvimento da educação permanente e ainda como espaço de desenvolvimento de projetos de investigação clínica, epidemiológica e administrativa. Barbosa (2009)

Adiciona-se a isto o fato de que hospitais continuam configurando-se como importantes protagonistas na geração de inovação em saúde, e o seu caráter estratégico, tanto no âmbito do Complexo Econômico-Industrial da Saúde como na agenda mais ampla de desenvolvimento nacional, é ressaltado.

Neste sentido, Djellal e Gallouj (2007) analisam cuidadosamente as inovações observadas dentre os complexos hospitalares. Os autores promovem a sistematização das informações sobre as inovações geradas no ambiente hospitalar, e também lançam luz àquelas decorrentes de uma visão mais sistêmica da atenção hospitalar. Ao superarem um olhar funcionalista da saúde, apontam o importante impacto dessas inovações sobre a reestruturação da prestação dos serviços em saúde e do próprio papel do hospital no bojo dos mesmos.

$\mathrm{Na}$ análise do impacto das tecnologias da informação e comunicação (TIC), por exemplo, os autores enfatizam as várias aplicações das TIC na saúde e suas consequências referentes às alterações de procedimentos e à infraestrutura necessária. 
Apontam não somente ganhos gerenciais decorrentes como também aqueles referentes às novas modalidades de atenção, a exemplo da redução de custo, do aumento da efetividade e (ou) do acesso à saúde.

Um dos efeitos deste novo formato de atenção (que envolve kits diagnósticos, monitoramento médico, equipamentos de diagnósticos automáticos, entre outras modalidades de telemedicina) é a possibilidade de expandir o acesso qualificado, para regiões privadas da infraestrutura de média e alta complexidade. As TIC podem configurar um importante fator redutor de custo, tempo de permanência em hospitais e dos riscos envolvidos, além de atuar também na promoção do acesso, entre outros benefícios. Podem, ademais, contribuir para a alteração da estrutura dos serviços em saúde, ilustrada pelo hospital dia, pelo atendimento domiciliar, por consultas remotas, entre outras. É por este motivo que Barbosa (2009) chega a afirmar que a integração das redes de atenção tem como pilar as TIC.

Mckee e Healy (2000), por sua vez, chamam a atenção para o impacto da TIC sobre o porte ideal do hospital do futuro. Reafirmam a necessidade de obter economia de escala nos serviços hospitalares, dada a intensificação tecnológica e a especialização clínica, enfatizando que recursos escassos e caros não têm como ficar dispersos em muitos hospitais de pequeno porte. De acordo com os autores, os estabelecimentos intensivos de cura estariam concentrados em poucos hospitais de grande porte com maior intensidade tecnológica.

Entretanto, na formulação de uma estrutura de cuidado mais preventiva e de promoção, em que a ênfase recai sobre uma atenção generalista, com maior interface humana do que tecnológica, os autores enfatizam que critérios de descentralização e desconcentração da atenção devem prevalecer, privilegiando o acesso da população à saúde.

Neste sentido, Barbosa (2009), em análise recente dos serviços em saúde, enfatiza a dinâmica internacional de 'redução espetacular' do número de leitos (conforme pode se observar no Gráfico 4) e de internações, a partir de 1980 e 1990, respectivamente. Afirma que as alterações refletem a incorporação de novas tecnologias que têm gerado mais eficiência na atenção extra-hospitalar, destacando as cirurgias ambulatoriais e internações domiciliares; assim como refletem uma maior importância atribuída à atenção básica, "a partir de unidades não hospitalares, sejam centros de saúde, ambulatórios, clínicas, consultórios e outros equipamentos sanitários". Enfatiza, ainda, a redução do tempo de internação, decorrente dos novos equipamentos, medicamentos e procedimentos, alterando a intensidade do uso de leitos hospitalares. 
Gráfico 04. Leitos hospitalares em países selecionados da Europa e no conjunto da União Europeia

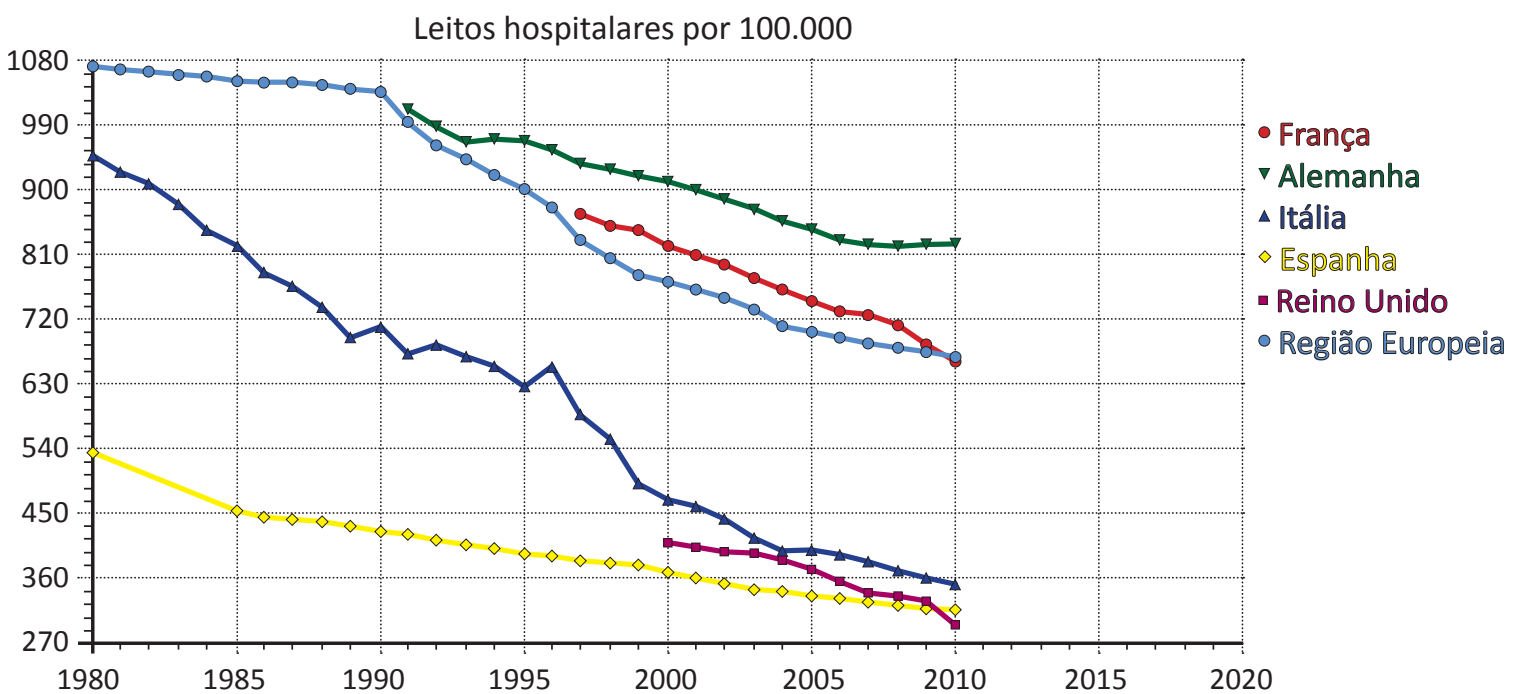

Fonte: WHO/Europe, European HFA Database, 2012, acesso em fevereiro de 2013.

Por fim, a título de sistematização das informações apresentadas neste tópico, há algumas considerações que interessam tecer. A primeira refere-se ao fato de que a dinâmica de reestruturação dos sistemas de saúde possui clara interação com as mudanças epidemiológicas, decorrente do envelhecimento da população e do estilo de vida contemporâneo. Observa-se que a orientação pela integração do sistema de saúde (com uma porta de entrada que vem se deslocando do hospital para a atenção primária) atende simultaneamente às necessidades de atenção de doenças crônicas e de redução dos custos.

Além disto, especialmente as inovações que têm o prestador de serviços como principal protagonista também parecem se orientar, de forma sistêmica, por estes novos desafios impostos pela necessidade de expansão do acesso e redução de custos. Vale ênfase em particular às inovações decorrentes das TIC, que conseguem contemplar os interesses coletivos, gerando tecnologias assistenciais mais eficientes e sustentáveis socialmente, conforme enfatiza Barbosa (2009).

Entretanto, uma análise mais sistêmica do Complexo da Saúde aponta para o fato de que a geração de inovação no âmbito dos tradicionais segmentos industriais da saúde - oligopólios caracterizados - ainda não se orienta por necessidades sociais coletivas. Isso porque sua agenda é essencialmente influenciada por um número muito restrito de atores globais, que pouco interagem com as necessidades de seu mercado consumidor, caracterizando um forte desequilíbrio de poder em relação às demandas sociais de uma dada nação. 
Do mesmo modo, Lobato e Giovanella (2008) ressaltam que a maioria dos sistemas de saúde exerce pouca interferência sobre a produção de insumos, controlada geralmente pelas indústrias multinacionais privadas (mobilizadas por interesses de uma minoria privilegiada). Viana, Nunes e Souza (2011) exemplificam tal questão ao afirmar que no período entre 1975 e 1997 apenas 0,1\% dos medicamentos lançados no mercado voltou-se para combater doenças tropicais, que afetam os mais pobres. Fato este agravado dado que no período, afirmam os autores, a população dos países de baixa e média renda (mais afetados por tais enfermidades) representava 85\% da população mundial.

Neste sentido, Fiori (1995) chama a atenção para os efeitos das influências externas sobre o modelo de Bem Estar, ressaltando a importância de "uma compreensão mais precisa dos limites e espaços de liberdade (...) para as economias, sociedades e estados situados na periferia de um capitalismo cada vez mais desregulado e global" (p. 27).

Assim, no que tange especificamente às inovações em saúde, que acabam envolvendo os interesses econômicos mais articulados e poderosos, notadamente os dos agentes econômicos privados internacionais, resta o importante desafio de intensificar a convergência das inovações no âmbito do CEIS e das necessidades de saúde coletiva. Ou seja, o desafio é fazer com que os interesses econômicos finalmente articulem-se aos sociais, e sejam por eles orientados.

Uma análise global dos serviços de saúde aponta que um dos desafios hoje enfrentados para a estruturação e gestão dos sistemas de saúde refere-se justamente a encontrar um meio de articular virtuosamente todos os componentes que impactam a estruturação dos serviços de saúde e os interesses por eles representados. Busca-se assim equilibrar os atores diversos atuantes nesta arena política e estabelecer uma dinâmica virtuosa entre as necessidades dos serviços de saúde e os demais segmentos do CEIS.

Para tanto, cabe aos Estados nacionais mediar estes interesses (de natureza social e econômica) visando ao estabelecimento de uma agenda virtuosa tanto na geração e incorporação de inovação quanto na reestruturação dos serviços em saúde que seja condizente com os novos desafios impostos pela mudança nas características epidemiológicas e demográficas da população. Para isso, deve o Estado orientar a dinâmica interna de inovação e de incorporação tecnológica em saúde, de modo que as mesmas atendam às necessidades impostas pelo novo perfil. 


\section{3 | PANORAMA BRASILEIRO DOS SERVIÇOS EM SAÚDE: DESAFIOS PARA SUA SUSTENTABILIDADE}

A partir da observação da dinâmica global do segmento de serviços, e considerando os componentes dos sistemas de saúde ${ }^{7}$ propostos por Lassey et al. (1997, apud IBAÑEZ, 2011), busca-se aqui analisar quais são os principais desafios do segmento de serviços em saúde no Brasil, considerando também sua função como parte de um sistema produtivo que precisa atender aos desafios da universalidade, integralidade e equidade de acesso por parte da população.

A saúde no Brasil, dadas as características do Sistema Único de Saúde (SUS), possui duas dimensões essenciais que a associam a uma nova aposta para o desenvolvimento do país. É parte da política social e do sistema de proteção social e importante fonte de geração de riqueza nacional (GADELHA, 2003; GADELHA et al., 2010), uma vez que a saúde conforma um complexo de atividades produtivas de bens e serviços que relaciona segmentos cruciais da sociedade contemporânea ${ }^{8}$, baseadas no conhecimento e na inovação, que são fatores de competitividade global.

Assim, o direito à saúde articula-se com um conjunto altamente dinâmico de atividades econômicas que podem se relacionar virtuosamente em um padrão de desenvolvimento que busque o crescimento econômico e a equidade como objetivos complementares. O crescimento da demanda por saúde - em função de alterações nas características epidemiológicas e, no caso brasileiro também decorrente de evoluções nas condições socioeconômicas da população - e a importância estratégica das indústrias do Complexo da Saúde na agenda de desenvolvimento representam importante conquista, mas também um desafio, uma vez que apontam para o acirramento dos interesses políticos em jogo.

Não surpreende, portanto, que Paim et al. (2011), em recente estudo sobre o sistema de saúde brasileiro, tenham apontado que os grandes desafios a serem enfrentados pelo SUS sejam de caráter essencialmente político. Salienta-se que as funções dos sistemas de saúde (financiamento, prestação de serviços, gestão e regulação) são influenciadas por relações políticas e econômicas que se manifestam por meio de interesses dos agentes e atores envolvidos direta ou indiretamente com os próprios sistemas (LOBATO e GIOVANELLA, 2008). Logo, tanto a existência quanto o desequilíbrio dessas forças devem ser considerados ao se avaliar as variáveis críticas dos serviços em saúde.

7 Acesso, relevância econômica e características do mercado industrial, pressão de custos, incorporação tecnológica, composição do financiamento e alterações das características epidemiológicas e demográficas.

8 Para maiores detalhes ver textos do segmento de base química e biotecnológica e aquele de base mecânica, eletrônica e de materiais do Complexo Econômico-Industrial da Saúde, elaborados respectivamente por Vargas et al. e Maldonado et al., no âmbito desta publicação. 
A análise da complexidade das dimensões da saúde como direito social, bem econômico e espaço de acumulação de capital (VIANA e ELIAS, 2007) não é trivial, já que envolve interesses de atores diversos que figuram o cenário político (público e privado, nacional e internacional) e possuem forças assimétricas. Quando da criação do SUS, por exemplo, o setor privado já se encontrava razoavelmente organizado, fruto das estratégias de desenvolvimento do sistema médico-previdenciário, o que historicamente tem resultado em uma relação hierárquica entre os interesses econômicos e os sanitários, privilegiando aqueles em relação à agenda social.

De acordo com Menicucci (2007), a configuração prévia do sistema de saúde marcou uma estrutura institucional que não só afetou a disposição e capacidade governamental, como influenciou a percepção e preferência dos usuários do sistema (path dependence ${ }^{9}$ ). A configuração de benefícios dispersos inviabilizou que a implementação do SUS pudesse contar com o apoio mobilizado do público alvo da política de saúde.

Sendo assim, o SUS depara-se com a própria impotência para atrair grupos sociais de maior poder aquisitivo, que passam crescentemente a buscar no mercado privado os serviços de saúde (FAVERET e OLIVEIRA, 1990). Dado o caráter do sistema de saúde brasileiro, marcado por relevante expansão da saúde suplementar (com 48,7 milhões de beneficiários em 2012) ${ }^{10}$, as características deste segmento privado impactam, sobremaneira, as características gerais de atenção à saúde.

Além disto, em decorrência da função regulatória da Agência Nacional de Saúde (ANS), a dinâmica do segmento de seguros e planos privados expressa a busca por ganho de escala. Como consequência, o mercado de saúde suplementar experimenta não somente importante movimento de concentração (15,7\% das operadoras são responsáveis por $80 \%$ dos beneficiários), ${ }^{11}$ como também de verticalização. Este movimento, aliado à importância do segmento privado na prestação e financiamento de serviços em saúde no Brasil, tem levado a que crescentemente os serviços de saúde também se orientem por lógica empresarial e industrial.

Vale notar que este mercado encontra-se particularmente associado ao dinamismo socioeconômico, dado que ele é concentrado em planos coletivos, financiados, em sua maior parte, por empresas (BARBOSA, 2009). Observe-se que esta característica contribui para acirrar as desigualdades existentes no âmbito do sistema de saúde, com importantes reflexos no território, conforme se depreende no Mapa 1.

9 Para mais detalhes sobre a teoria "path dependence" ver Pierson (2000).

10 Fonte: Sistema de Informações de Beneficiários/ANS/MS. Acesso em fevereiro de 2013. Nota: beneficiários em planos privados de assistência médica com ou sem odontologia em dezembro de 2010.

11 Cadastro de Operadoras/ANS/MS e Sistema de Informações de Beneficiários — ANS/MS, acesso em fevereiro de 2013. 
Mapa 01. Taxa de cobertura dos planos de assistência médica por Unidades da Federação (Brasil — setembro/2012)

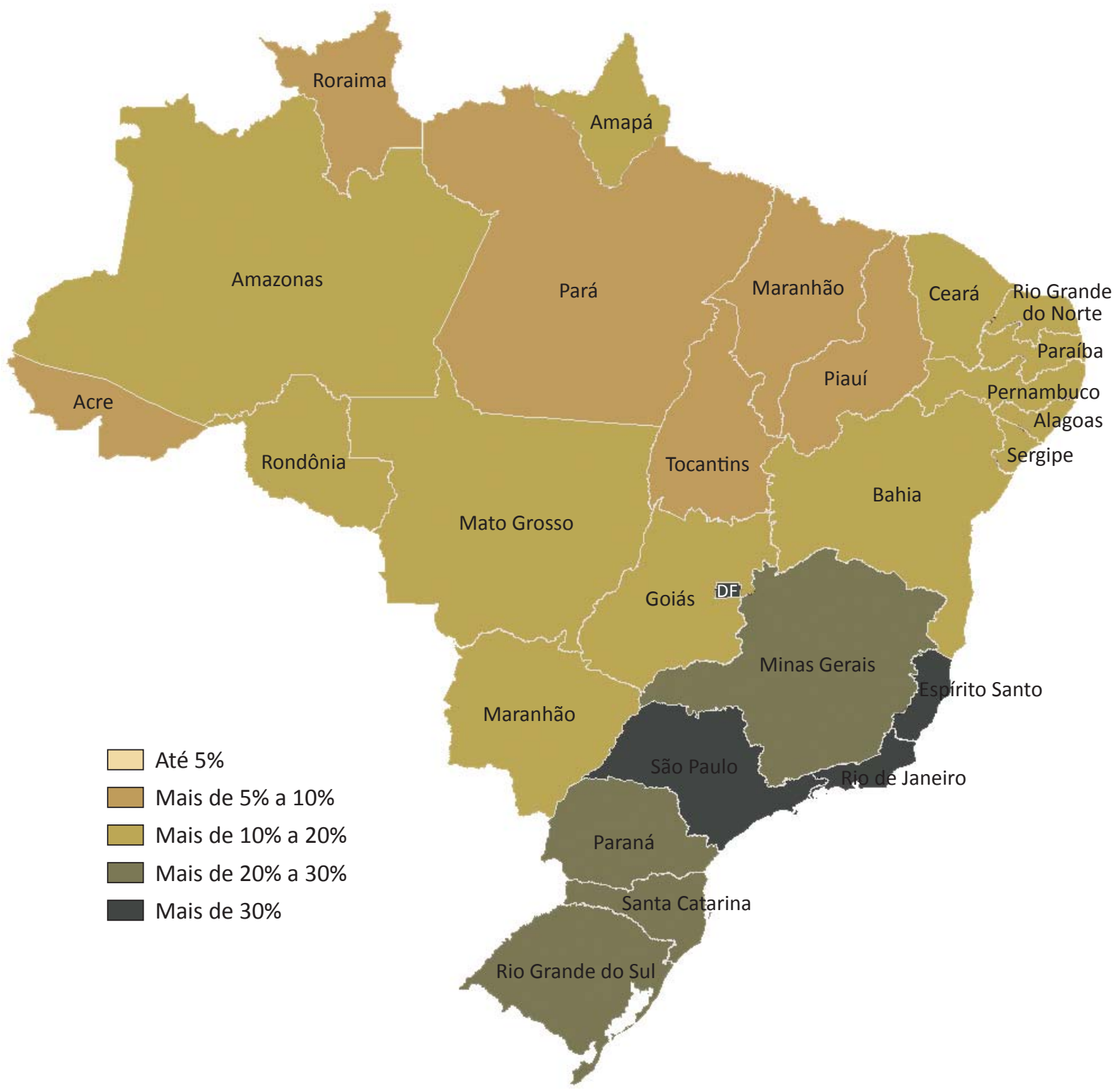

Fonte: Sistema de Informações de Beneficiários/ANS/MS — ANS/MS — 09/2012 e População — IBGE/2012.

Assim, desigualdades provenientes da cobertura à saúde por planos privados acabam sendo tanto de renda, quanto territoriais ${ }^{12}$, uma vez que: a) o acesso

12 De acordo com ANS (2013), em 2012, 39\% da população residente na região Sudeste era coberta por planos de saúde, enquanto somente $12 \%$ e $10 \%$ possuíam esta cobertura nas regiões Nordeste e Norte, respectivamente (dados populacionais de 2010, de acordo com IBGE, 2010). 
à saúde suplementar concentra-se normalmente em grupos populacionais com melhores condições socioeconômicas ou naqueles que fazem parte da estrutura formal de emprego no Brasil; e b) observa-se relevante concentração regional da cobertura destes planos, disponíveis em apenas 30\% dos municípios brasileiros (ALBUQUERQUE et al., 2008, apud VIANA e MACHADO, 2008, p.670).

A acomodação do sistema brasileiro — em que se observa a coexistência da incapacidade da prestação de serviços públicos universais de qualidade com a aquisição da saúde por parte de camadas mais privilegiadas junto aos prestadores privados - traz consigo essenciais perdas políticas e sociais. Estas perdas são decorrentes da exclusão da participação de setores potencialmente reivindicatórios no sistema público e da consequente coibição do estabelecimento de relações solidárias, ambas decorrentes das mencionadas características do sistema de saúde brasileiro. (FAVERET e OLIVEIRA, 1990).

A análise da dinâmica dos interesses mercantis e capitalistas nos espaços sociais e, mais importante, a reflexão de como suas contradições podem ser reguladas fazem parte do processo de compreensão de que desafios ainda precisam ser superados pelo SUS. Note-se que, nesta análise, o papel do Estado exerce protagonismo central.

Um importante desafio para a implementação do SUS, cuja superação passa pelo exercício de decisão política do Estado, refere-se ao subfinanciamento da saúde, que impede o estabelecimento de relações de equidade e integralidade no acesso universal. A proporção do gasto governamental brasileiro em saúde é incompatível com qualquer sistema universal existente no mundo. Nos países desenvolvidos, o gasto público representa mais de 70\% do gasto em saúde (Gráfico 5), sendo que não há no mundo nenhum sistema universal em que o financiamento público esteja abaixo deste patamar.

No Brasil, a participação pública nos gastos em saúde situa-se em torno de 47\% (OMS, 2011), apesar das extremas iniquidades no bojo da sociedade brasileira e do fato de que $74,9 \%$ da população brasileira dependem exclusivamente do SUS (ANS, 2013).

Além disto, estas questões são agravadas ao se observar as mudanças significativas no perfil de financiamento público (Gráfico 6), decorrentes das características intrínsecas ao processo de descentralização brasileira, que vêm contribuindo para uma base regional desigual deste financiamento (UGÁ e MARQUES, 2005; MACHADO e VIANA, 2009). Adicione a este fato as distorções na alocação de recursos em saúde referente ao dispêndio familiar em saúde, concentrado tanto territorialmente quanto de acordo com as faixas de renda. Depara-se, portanto, com outro grande desafio do SUS, referente à superação das desigualdades intrínsecas à prestação da atenção à saúde para a população brasileira (PIOLA et al, 2009, p.35). 
Gráfico 05. Despesa total em saúde como percentual do PIB e composição (pública e privada) — Brasil e Blocos Econômicos (2009)

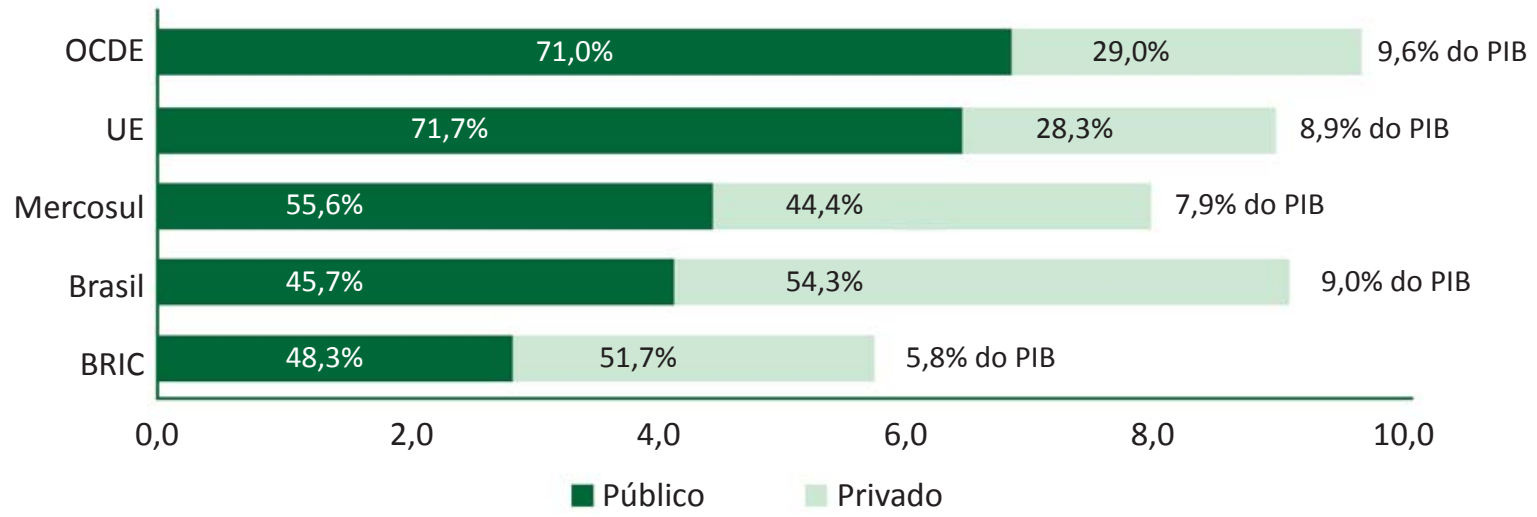

Fonte: Elaborado por GIS/ ENSP/FIOCRUZ, a partir de dados da WHO, 2011.

Gráfico 06. Evolução da composição do gasto público no SUS por esfera de governo (em \%)
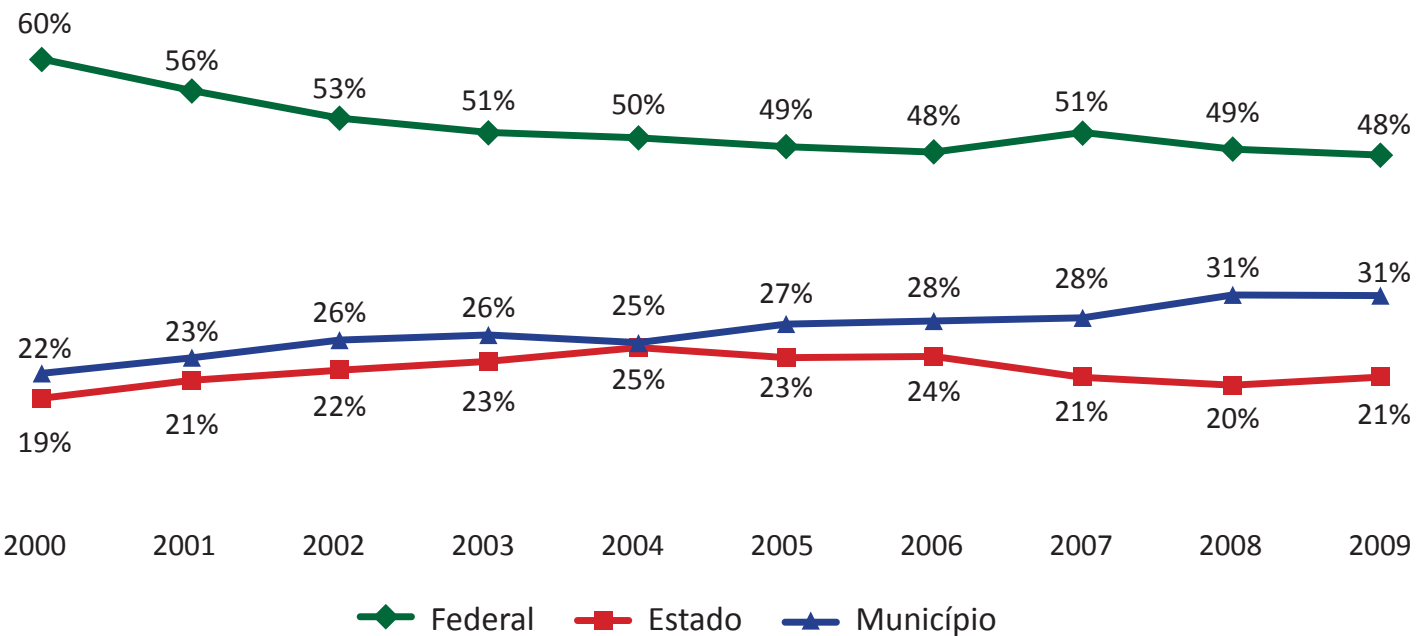

Fonte: Elaborado por GIS/ESNP — FIOCRUZ, 2012, a partir de dados do SIOPS; SPO/SE; FNS/MS. Acesso em Fevereiro de 2012 para dados de 2000 a 2006; IBGE 2012 para dados de 2007 a 2009.

A reversão destas iniquidades exigiria aquilo que Marx e Engels qualificaram como "medidas que, do ponto de vista econômico parecerão (...) insustentáveis" (BOYLE, 2006, p. 54). Refere-se aqui à necessidade de considerar fatores outros que não a lógica do capital (de impulso à competitividade econômica nacional) para a distribuição dos investimentos em saúde.

Atualmente, o pacto político-social constitucional que define um sistema universal coabita com a estrutura de dispêndio de um sistema de saúde mercantil, cujo peso do gasto privado é incompatível com a universalização do 
acesso (GADELHA et al., 2012). A significativa limitação financeira ao investimento no sistema e sua direção fragmentada impedem a reestruturação da rede segundo uma lógica nacional regionalizada (GADELHA et al., 2009b), comprometendo os objetivos de regionalização previstos nos princípios básicos do SUS e reforçados pelas políticas dos últimos anos. Como reflexo disto, as diferenças regionais permanecem e o acesso aos serviços e a qualidade dos mesmos ainda são desiguais ao longo de todo território nacional.

Assim, do ponto de vista regional, praticamente todas as informações disponíveis apontam para uma grande rigidez na oferta do SUS, marcando a dificuldade de se reverter a concentração territorial dos serviços em saúde. Ilustra este fato a evolução da composição regional da produção ambulatorial, das consultas médicas, da disponibilidade de tomógrafos e mamógrafos, do número de clínicas e ambulatórios especializados, dos leitos de UTI, das internações cirúrgicas oncológicas, para citar alguns indicadores da prestação de serviços de saúde. Como uma consequência parcial, no Brasil, essas iniquidades também podem ser aferidas a partir da distribuição regional das taxas de mortalidade infantil e da esperança de vida ao nascer. Esta última evidenciou, em 2008, uma diferença de cinco anos entre as regiões Nordeste e Sul (GADELHA e COSTA, 2012).

Além da questão do subfinanciamento, outro importante desafio a ser ressaltado refere-se à fragilidade do arcabouço político institucional relacionado à incorporação de tecnologia do Complexo da Saúde. Na atualidade, o aumento de tecnologias produzidas na área de saúde tem sido associado tanto à queda na mortalidade e ao aumento do volume de conhecimento produzido sobre tecnologias médicas, como também à majoração do custo da assistência médica. Assim, vale particular atenção para a necessidade de se promover a superação da baixa capacidade de produção e inovação dos segmentos industriais do complexo da saúde nacional, da pouca cultura de inovação do empresariado local, da inadequação do marco regulatório no campo da inovação e dos escassos mecanismos de fomento à inovação aliados a pouca tradição brasileira de incorporar, racionalmente, as tecnologias em saúde.

Deste modo, outro empecilho ao desenvolvimento do SUS, referente ao aparato institucional do Complexo da Saúde, diz respeito à necessidade de avançar na efetividade da atuação do Estado no que tange à qualificação de seu aparato regulatório, acentuação do uso de seu poder de compra, adequação de seu modelo de gestão e fortalecimento da institucionalização do CEIS. Sem esses avanços, a relação entre os interesses públicos e privados tende a manter-se desequilibrada, com custos insustentáveis para a saúde pública e o sistema de bem-estar social ${ }^{13}$.

13 Vale notar que este texto foi originalmente elaborado em 2011. Desde então o Estado vem intensificando a utilização de seu poder de compra e promovendo adequações no arcabouço regulatório, entre outras iniciativas que refletem a crescente institucionalização da saúde na agenda de desenvolvimento nacional. Ainda que haja 
Há, desta forma, muito que se avançar para superar a vulnerabilidade da base de inovação em saúde no Brasil. Caetano (1998) ressalta que, apesar da importância do processo de inovação tecnológica em ambiente globalizado, pouco se sabe a respeito dos fatores que interferem no progresso técnico na área de saúde. Lehoux (2008, apud VIANA et al., 2011) chama a atenção para o descompasso entre a agenda de inovação e os interesses coletivos da saúde, fato decorrente de características específicas das políticas de C\&T e de saúde, no que tange à geração de inovação.

Assim, cresce a importância da adequação de uma ainda jovem política de incorporação tecnológica no Brasil, sem a qual prevalecerá a observada incorporação de medicamentos que não refletem a especificidade epidemiológica, geográfica ou socioeconômica brasileira (VIDOTTI et al., 2008). Esta adequação também contribuirá para diminuírem os processos de incorporação tecnológica determinados a partir da compreensão de juízes do que seria a defesa de um preceito constitucional de acesso integral e universal à saúde (conhecidos como judicialização da saúde). De forma análoga, materiais e equipamentos médicos de efetividade não comprovada, e, muitas vezes, incompatíveis com a estrutura epidemiológica ou tecnológica vigente no país, seguirão sendo incorporados e subutilizados pelo SUS.

No caso específico do Brasil, esta situação agrava-se devido ao estágio ainda atrasado de desenvolvimento das indústrias nacionais do Complexo Produtivo da Saúde, pressionando, sobremaneira, os custos da prestação dos serviços, e provocando aumento substantivo no déficit comercial brasileiro, que chega a ser superior a US\$10 bilhões em $2012^{14}$.

Deste modo, o sistema fica crescentemente dependente de importações nos segmentos farmacêuticos e de equipamentos e materiais médicos, levando à falta de autonomia na definição sobre os insumos que melhor atenderiam a população nacional. Ademais, a baixa competitividade da indústria nacional impõe desafios também quando se observa que, em função das mencionadas características demográficas e epidemiológicas, há um aumento expressivo do custo para a provisão da saúde. A titulo de ilustração, Victora et al. (2011) ressaltam um "crescimento assustador na fatia do orçamento nacional associado a equipamentos médicos e insumos (medicamentos, kits diagnósticos, vacinas, etc.), de 5,8\%, em 2003, para 12,3\%, em 2009".

Enfatiza-se desta forma, a vulnerabilidade da política de saúde, dada a conjugação do aumento da demanda, da incorporação de novas tecnologias e da baixa autonomia da base produtiva da saúde nacional, estabelecendo desafios à sustentabilidade e configurando real ameaça aos princípios de universalização e

muito que se avançar, e que, ademais, será necessário verificar a efetividade de tais ações no tempo devido, as iniciativas implementadas no período refletem a percepção de que é necessário qualificar e intensificar o protagonismo do Estado na acomodação dos interesses diversos que influenciam a agenda da saúde.

14 Para maiores informações, ver as análises de Maldonado et al. e Vargas et al. no âmbito desta publicação. 
integralidade do SUS. Adiciona-se a isto a debilidade na eficácia dos atendimentos referente aos limites impostos pela política de assistência farmacêutica, dado que, de acordo com Viacava et al (2011), apenas 45\% dos pacientes atendidos no SUS receberem todos os medicamentos prescritos.

Vale mencionar que importantes orientações macropolíticas visando ao fortalecimento da base produtiva de saúde têm sido instituídas nos últimos anos (em particular a partir de 2007, quando o Estado começou a atribuir centralidade ao desenvolvimento do Complexo da Saúde).

Observam-se, decorrentes disto, iniciativas de grande relevância para superar o estágio de desenvolvimento da geração de inovação no âmbito do complexo produtivo nacional em saúde, referentes: ao estabelecimento de parcerias para o desenvolvimento produtivo (PDP) visando internalizar a produção de fármacos no país; às iniciativas diversas para utilizar o poder de compra do Estado de forma mais sistêmica, a exemplo da lei 12.349/2010, regulamentada pelo Decreto 7546/2011; ao significativo apoio à inovação pelos produtores públicos e à rede de laboratórios oficiais; à crescente articulação da política de assistência farmacêutica para a transformação da base produtiva nacional de medicamentos; e à realização de investimento de grande importância para fortalecer a base nacional de conhecimento em saúde, para citar principais iniciativas setoriais.

Vale ainda particularizar a importância da entrada de instituições da área econômica e de C\&T na priorização da produção e da Inovação em Saúde, com destaque para a ação do BNDES (Profarma II) e para a criação de fundos de subvenção de C\&T para a saúde.

Entretanto, e a despeito dessas iniciativas, ainda se corre sério risco de reversão neste processo de fortalecimento da base produtiva de saúde, em função da falta de uma base endógena de inovação. Note-se que o crescente déficit do CEIS indica que os instrumentos implementados ainda são insuficientes para dotar de autonomia o sistema nacional de saúde.

O indicativo é que a esfera federal precisa aprimorar sua atuação intersetorial, de modo a evitar, por exemplo, o descompasso das políticas de inovação no âmbito da saúde e de C\&T; e a melhorar sua capacidade de formulação das políticas nacionais e, principalmente, de regulação do sistema, estabelecendo formas democráticas e coerentes de organização federativa.

Uma vez mais, enfatiza-se que os grandes desafios do SUS encontramse na esfera política, e até que se decida que modelo de bem-estar realmente se deseja no Brasil, a probabilidade de uma ineficiência sistêmica, acompanhada de uma fragmentação das ações em saúde, parece incontornável. 
Neste sentido, Albuquerque (2007), revisitando as teorias de Celso Furtado, aponta para a necessidade de promoção do desenvolvimento tecnológico articulando os sistemas de inovação e bem-estar social. O autor entende que desta forma superarse-á a histórica polaridade modernização-marginalização, observada desde o primeiro ciclo desenvolvimentista brasileiro, no qual o processo de modernização tecnológica se deu simultaneamente ao de marginalização social.

No que tange ao SUS, deve-se ressaltar que a despeito das limitações referentes ao financiamento, à base de inovação, e às relações entre os interesses públicos e privados da saúde, o Sistema Único de Saúde foi bem sucedido em melhorar de forma significativa

o acesso à atenção básica e de emergência, atingir uma cobertura universal de vacinação e assistência pré-natal e investir fortemente na expansão de recursos humanos e de tecnologia, incluindo [significativos] esforços para fabricar produtos farmacêuticos mais essenciais ao país. (Paim et al., 2011)

Diversos são os indicadores de uma evolução expressiva dos serviços oferecidos à população usuária do SUS, o que é vital para o acesso do cidadão aos serviços de saúde, considerando que apenas $25 \%{ }^{15}$ da população brasileira possuem planos de saúde com registro na Agência Nacional de Saúde Suplementar (ANS) e que diversos serviços de maior complexidade são ofertados apenas no sistema público (ANS, 2012).

Podem ser citados alguns elementos importantes que marcam a evolução recente da atenção à saúde, como, por exemplo, o fato de que a produção de serviços ambulatoriais do SUS elevou-se em 62\% de 2003 a 2009 em número de atendimentos, chegando a 3,2 bilhões de procedimentos ao longo de último ano; e foram realizadas 486 milhões de consultas médicas em 2009. Conforme argumentação prévia, há muito que se avançar para superar as desigualdades regionais, exemplo disto é o fato de o número de consultas por habitante no Sudeste ser sete vezes maior do que aquele observado na região Norte (GADELHA e COSTA, 2010).

No que se referem às internações hospitalares, os dados, em uma primeira abordagem, parecem contraditórios com esta expansão verificada em nível ambulatorial. O número de internações caiu 5\% de 2003 até 2009 (GADELHA e COSTA, 2010), tendo se observado expansão somente na região Norte, o que sugere que o fortalecimento das ações da atenção básica e das unidades pré-hospitalares de

15 Fonte: Sistema de Informações de Beneficiários/ANS/MS — 09/2012 e População — IBGE/Datasus/2012, acesso em fevereiro de 2013 Nota: Taxa de cobertura refere-se a percentual da população coberta por plano privado de saúde. 
urgência e emergência (Serviço de Atendimento Móvel de Urgência — SAMU e Unidades de Pronto Atendimento - UPA) possivelmente ocasionou uma diminuição relativa na intensidade das internações. Em todo caso, conforme será analisado adiante neste texto, a aposta aqui é da existência de um paradoxo entre a mudança desejável no perfil da assistência e a permanência de problemas de acesso às internações.

Ademais, vale particular menção aos avanços observados no âmbito da assistência farmacêutica, o que pode ser observado pela crescente participação das despesas voltadas para a promoção do acesso a medicamentos, além de outros produtos essenciais, como vacinas, no orçamento do Ministério da Saúde.

Vale enfatizar que talvez seja no campo dos serviços de maior complexidade, em conjunto com a atenção básica, onde o SUS mostra de modo mais acentuado sua potência e importância, em que pesem todos os problemas de qualidade e de acesso. Entre outras, as áreas de cardiologia, de oncologia e de transplantes, e a oferta de leitos complementares para ações de alta complexidade (UTI e outras) refletem este papel do SUS, sendo o acesso promovido único no contexto dos países de baixa e média renda e das economias emergentes.

Outro aspecto digno de nota no SUS refere-se ao seu movimento de reforma visando atender aos desafios impostos pelas mudanças epidemiológicas aliadas às limitações de financiamento. Neste sentido, observa-se a convergência do perfil de reestruturação do SUS com aquela observada em âmbito internacional.

Assim, a necessidade de tornar mais racional a distribuição dos recursos mobilizados pelos sistemas de saúde levou a um movimento, também no Brasil, de marcante reconfiguração dos modelos de atenção no bojo dos sistemas de saúde. Sua ideia norteadora é o fortalecimento da integração das redes de saúde, a partir da diminuição progressiva do papel dos hospitais, do incremento do papel dos cuidados extra-hospitalares e da valorização da atenção básica. Busca-se superar a ineficiência característica da preferência da população de utilização do hospital como porta de entrada do sistema de saúde, ocasionando custos expressivos para atenção que poderia ser realizada em postos de saúde, em clínicas especializadas ou em ambulatórios. ${ }^{16}$ A proposta é atribuir racionalidade a um sistema que passaria a ter uma porta de entrada definida e um sistema de referência e contra referência, conforme tratado no primeiro tópico deste texto.

Um sistema integrado de saúde passa também a ter sua importância enfatizada a partir da alteração no perfil de demanda por serviços de saúde,

16 De acordo com análise setorial do Valor econômico, realizada em 2008, no Brasil, 67\% dos gastos em saúde são consumidos em hospitais, sendo que a média da OCDE é de 55\%, além disto, 30\% das internações não apresentam necessidade comprovada. Há que se considerar que questões diversas refletem a eficácia da aplicação de recursos nos hospitais, a exemplo da taxa de ocupação, porte dos hospitais, entre outros. De toda forma, o uso inapropriado destes estabelecimentos no Brasil é bastante característico do modelo médicohospitalar curativo ainda vigente no país (VALOR, 2008). 
representada pelo crescimento da participação das doenças crônicas, que exigem cuidados de caráter continuado, e aquelas decorrentes de estilo de vida. A integração do sistema conforma-se mediante a incorporação de novas tecnologias, readequação interna do espaço físico, novas formas de prestação de cuidados, além da busca de novos formatos e ferramentas gerenciais, conforme detalhado na análise global dos serviços em saúde. Assim, avanços científicos e tecnológicos, anteriormente observados somente no interior dos hospitais, passaram a ser gradativamente deslocados para outros ambientes, levando, também no Brasil, a inovações na prestação da atenção à saúde (BARBOSA, 2009).

Desta forma, nota-se no Brasil movimento semelhante à tendência mundial, no que se refere às inovações nas prestações de serviços em saúde, em que a busca pelo aumento do acesso, concomitante à racionalização dos custos, passa pela incorporação da tecnologia da informação, assim como de inovações para tornar mais eficaz a estrutura de atenção, a exemplo da telemedicina, diagnósticos remotos, criação de hospitais-dia, procedimentos de maior complexidade em estruturas ambulatoriais, etc.

A grande mudança ocorrida no modelo de atenção no que se refere à prestação de serviços foi a crescente ênfase nas ações de atenção básica, com a criação do Programa Saúde Família (PSF), sua principal estratégia, e sua articulação com outros serviços visando arrefecer a busca de atenção no âmbito da infraestrutura hospitalar.

De acordo com Paim et al (2011), o PSF tem atuado na "reorganização de unidades básicas de saúde para que se concentrem nas famílias e comunidades e integrem a assistência médica com a promoção de saúde e as ações preventivas". Além disto, por meio da Estratégia Saúde da Família ${ }^{17}$, o MS tem implementado, de forma preventiva, diretrizes clínicas voltadas para a gestão de doenças crônicas (PAIM et al, 2011).

Atualmente 94,8\% dos municípios brasileiros são cobertos pelo Programa, que atende 54,6\% da população brasileira (MS, 2013). Reforçando esta orientação, houve marcante expansão também de iniciativas de média complexidade, referentes às unidades fixas e móveis de urgência e emergência — respectivamente as UPAs e o SAMU - configurando-se como iniciativas potenciais para transformar a centralidade do hospital e estabelecer a integração do sistema a partir das reais necessidades de saúde da população, e não via indução da demanda.

A proposta desta reestruturação do SUS é a de definir a atenção básica como a porta de entrada do sistema de saúde, a exemplo da Inglaterra, de modo a racionalizar o uso do mesmo, orientado pela necessidade da população e promover a redução de custos desnecessários.

17 Atualmente, o Programa Saúde da Família (PSF) é denominado de Estratégia Saúde da Família. Neste texto foram utilizadas as duas terminologias para se referir às ações no âmbito do "Saúde da Família". 
Vale notar que mudanças voltadas à integração do sistema com a porta de entrada na atenção básica já podem ser observadas no país. Como consequência, uma proporção razoável de pessoas deixou de usar os "ambulatórios hospitalares como sua fonte habitual de cuidados” e, no período entre 1998 e 2008, o número de brasileiros que passaram a se referir à atenção básica como seu serviço habitual de saúde passou de 42\% para 57\% dos usuários (VIACAVA et al, 2010; PAIM et al, 2011) ${ }^{18}$. A despeito destes avanços, a atenção terciária e hospitalar ainda exerce forte influência sobre o sistema de saúde como um todo, assim como no caso da dinâmica global, e o sistema permanece centrado no hospital, conforme enfatizam os autores. De acordo com La Forgia e Couttolenc (2009), hospitais permanecem no centro da atenção à saúde brasileira e respondem por 2/3 dos gastos do sistema e por parte significativa dos serviços produzidos. De forma análoga ao resto do mundo, é o ambiente hospitalar que reúne os principais talentos, configurando-se como importantes centros de treinamento no país. Assim, também no Brasil, os hospitais ainda são protagonistas privilegiados nas etapas de geração e incorporação tecnológica, situando sua relevância na análise da dinâmica de geração de inovação em saúde.

Ainda que o Brasil siga a tendência mundial ao direcionar a readequação do seu sistema de saúde para as novas demandas epidemiológicas e de redução de custos, Barbosa (2009) ressalta preocupação com a reestruturação da infraestrutura hospitalar brasileira. O autor aponta que nas últimas décadas a esperada diminuição de leitos por habitantes não veio acompanhada de adensamento tecnológico no cerne das estruturas hospitalares ${ }^{19}$. Sugere ainda que uma explicação possível para a dinâmica brasileira é sua base municipalista, que poderia estar induzindo o fomento de hospitais locais de pequeno porte e densidade limitada. Hipóteses estas corroboradas por Paim et al. (2011) ao apontarem que na atualidade cerca de 60\% dos hospitais brasileiros possuem 50 leitos ou menos e que, após a descentralização hospitalar, foram criados novos hospitais com médias de 35 leitos cada. Os autores afirmam ainda que estes novos hospitais, de menor dimensão, tendem a ser menos efetivos que os maiores.

Tais constatações permitem concluir que a reestruturação do modelo hospitalar observada em anos recentes no país não é condizente com as necessidades de atenção à saúde, já que as características epidemiológicas, o aumento de serviços extra-hospitalares, assim como a ambulatorização de procedimentos, exige maior densidade tecnológica nos hospitais. Para Barbosa (2009), este é o grande desafio para a gestão hospitalar do futuro imediato, que também encontra limitantes referentes à necessidade de contenção de custos. O impacto deste segmento da prestação sobre

18 Paim et al. (2011) enfatizam ainda o sucesso de políticas específicas voltadas para a prestação dos serviços de atenção secundária. Tal resultado, mensurável pela expansão da oferta dos mesmos, ocorreu a despeito da grande dependência do SUS em relação ao setor privado (pouco interessado nestes procedimentos) e de um arcabouço regulatório ainda por ser aprimorado.

19 Este adensamento poderia ser observado a partir do aumento do número de leitos por hospital, em função da busca de promover economias de escala. 
os gastos é enfatizado, de acordo com La Forgia e Couttolenc (2009), tanto porque representa parte significativa dos recursos globais do sistema como porque no Brasil o setor público responde por 60\% deste gasto. Os autores enfatizam, por fim, que unidades de saúde voltadas para os casos agudos de atenção permanecem dominando o cenário hospitalar e que, mesmo entre prestadores públicos, os arranjos em redes integradas entre os diferentes níveis de complexidade do sistema são raros.

Assim, a análise do caso brasileiro - voltada para verificar os desafios futuros para a efetivação da saúde enquanto elemento estruturante do sistema de Bem Estar brasileiro, e também como integrante de um sistema de grande relevância econômica e estratégica para o desenvolvimento do país - aponta algumas variáveis que precisam ser consideradas para se traçar o cenário futuro dos serviços em saúde no país.

Note-se que a crescente demanda por serviços em saúde e o conjunto de interesses públicos e privados por esta articulados enfatizam a importância do papel do Estado no financiamento, estrutura de prestação de serviços, marco regulatório, entre outras variáveis críticas da saúde.

Ainda que muito se tenha avançado na expansão do acesso no país depois da implementação do SUS (que se constitui de fato em um sistema paradigmático), os resultados referentes à superação das desigualdades (de renda e regionais), em seu bojo, são pífios. Situação esta agravada pela falta de apoio político ao SUS por parte da população e por ser o sistema de saúde brasileiro fragmentado, bastante afeto aos interesses privados, dado que não se pode avaliar os serviços em saúde no país sem considerar a dinâmica do sistema suplementar privado.

Essas desigualdades, tanto decorrentes do sistema público quanto do suplementar, geram impactos que extrapolam a já relevante questão da injustiça social que afeta grupos menos privilegiados e localidades de acesso mais remotos. Elas também limitam a capacidade de reestruturação de todo o sistema de saúde. Tais desigualdades afetam também a possibilidade de se implantar importantes inovações no âmbito do sistema de saúde, a exemplo da assistência domiciliar e demais iniciativas que pressupõem conectividade e infraestrutura mínimas adequadas. Note-se que estas iniciativas não somente têm conseguido avançar na individualização do acesso, mas também na redução dos custos do mesmo, ambas variáveis centrais para os desafios presentes e futuros da prestação de cuidados à saúde.

Esta situação agrava-se quando se constata que questões referentes ao modelo de gestão e aos limites de financiamento do SUS têm impactado na reestruturação do parque hospitalar brasileiro, que não tem promovido adensamento tecnológico coerente com as características epidemiológicas da população.

Note-se que a questão do financiamento é central na atualidade, tanto no Brasil quanto no mundo, dada a transição demográfica vivida e inadequações 
observadas nos modelos de atenção e nos critérios de incorporação tecnológica. No caso específico brasileiro, o patamar de financiamento por parte do setor público é incompatível com um sistema que se pretende universal e integral, além de equânime.

Ainda no que se refere à tecnologia em saúde, a fragilidade da base produtiva da saúde no Brasil, em que pesem iniciativas diversas por parte do Estado, pauta-se como uma importante vulnerabilidade da política de saúde. Assim, aprimorar a atuação do Estado em relação à geração de inovação em saúde, o fato de que esta deve subordinar-se aos interesses sociais coletivos, e demais atribuições no sentido de fortalecer o marco regulatório, relacionam-se diretamente com a sustentabilidade do SUS.

Em síntese, estas são algumas questões centrais a serem avaliadas quando se pensa na dinâmica destes serviços em saúde em cenários futuros.

\section{4 | PERSPECTIVAS 2022/2030}

A centralidade da saúde em uma agenda mais ampla de desenvolvimento foi reconhecida, no Brasil, por diversos campos de atuação, em especial a partir de $2007^{20}$. Como consequência, a saúde, em uma abordagem sistêmica que a considera como parte de um complexo sistema político, social e econômico, configura-se como área prioritária de diversas políticas, além daquela constante na agenda setorial. Adicione-se a isto que, especialmente na última década, o protagonismo assumido pelo Estado brasileiro na retomada de uma agenda de desenvolvimento nacional torna ainda mais importante a discussão de cenários futuros da saúde no Brasil.

Ademais, as mudanças no perfil demográfico e epidemiológico, a profusão de novas - e caras - tecnologias no mercado, incorporadas, muitas vezes, sem uma profunda análise da relação custo-efetividade, as questões específicas relativas ao estilo de vida das pessoas e também o impacto da globalização tem tensionado os sistemas de saúde no Brasil e no mundo.

Estas variáveis, articuladas, enfatizam a insustentabilidade financeira, além da inadequação do modelo ainda vigente dos sistemas de saúde em relação ao novo perfil demográfico e epidemiológico. Esta realidade tem situado no centro da pauta das políticas nacionais de saúde dos diversos países a necessidade de reestruturação dos sistemas de prestação de serviços em saúde, conforme se argumentou neste estudo.

No âmbito desta análise, importa verificar a evolução das variáveis críticas para os serviços em saúde brasileiros, apontadas no tópico anterior, para os

20 Para maiores detalhes, sugere-se a leitura de Saúde e desenvolvimento, de Gadelha e Costa (2013), um dos capítulos desta publicação. 
períodos de 2022 e 2030. Estes cenários baseiam-se em uma definição pouco tradicional dos serviços de saúde, entendendo-os como parte e como elemento articulador de um complexo produtivo, e envolvendo uma gama de interesses muitas vezes dicotômicos.

Parte-se também do reconhecimento de que o modelo de atenção à saúde vigente, voltado para o tratamento intensivo, não é mais capaz de atender as demandas atuais e aquelas previstas para o futuro. Estimativas diversas apontam que nos próximos vinte anos o perfil saúde-doença nacional terá crescente participação de doenças crônicas, aquelas vinculadas a padrões específicos de morbimortalidade, mentais e as não transmissíveis (hipertensão, diabetes, etc), revelando a necessidade de ter um sistema com maior ênfase na prevenção e na promoção. De acordo com McKee e Healy (2000), este novo sistema terá maior interface humana do que tecnológica, e recorrerse-á a desconcentração e descentralização na busca de favorecer o acesso da população.

Quando se pensa em cenários prospectivos, pode-se considerar uma hipótese em que, a despeito da continuidade das políticas atuais, os limitantes ao plano estabelecimento do Estado de bem estar social permanecem, constituindo-se como um cenário mais regressivo. Há também um cenário mais otimista - e factível — em que se observaria um conjunto de mudanças, reformas e iniciativas no sentido de superar as barreiras atuais. Neste, os desafios futuros seriam superados e finalmente o país conseguiria concretizar o modelo de estado de Bem Estar preconizado na Constituição Federal.

Neste sentido, ou seja, da adequação dos sistemas de saúde às necessidades futuras, contemplando as mudanças demográficas e epidemiológicas, o sistema de saúde teria que contemplar linhas de cuidado e promover a estruturação de redes integradas para dar conta de garantir a integralidade da atenção à saúde.

Em estudo voltado para a análise dos desafios decorrentes da necessária reestruturação dos sistemas de saúde e as tecnologias por ele articulados, a IBM (2006) apontou que já em 2015 os pacientes crônicos aumentariam seu protagonismo no controle de suas enfermidades por meio da utilização de tecnologia da informação. E que, ademais, sistemas informacionais, baseados em dados de monitoramento e diagnósticos domésticos facilitariam o controle dessas doenças de forma mais efetiva e com menos recursos.

Dadas as características nacionais, no Brasil de 2015 esta reformulação no modelo assistencial ainda estaria restrita a grupos e regiões mais privilegiados, porém, em 2030, a melhoria da infraestrutura instalada no país (alcançando regiões mais remotas) permitiria uma distribuição mais equânime do acesso remoto especializado aos serviços de saúde.

A reestruturação do modelo de atenção à saúde ocorreria em parte graças às novas tecnologias de informação que, junto com a nanotecnologia e a biotecnologia, a genômica e a medicina regenerativa seriam aquelas que mais trariam mudanças na 
prestação de serviços em saúde. Estas novas tecnologias, em conjunto, influenciariam e conduziriam, em muitos casos, uma reestruturação da produção de materiais, insumos e medicamentos, sendo que as TIC, em particular, continuariam se configurando como importantes protagonistas na resposta às necessidades de reestruturação dos serviços em saúde.

Gallouj (2002, apud BARBOSA, 2009) estima que aproximadamente 60\% das atividades estabelecidas no âmbito dos serviços de saúde envolvem trocas de informações passíveis de automação, o que aponta para a potencialidade de reforma dos sistemas de saúde a partir da difusão do uso das TIC. Como consequência da intensificação do uso da telemedicina, diagnósticos remotos, cirurgias ambulatoriais, novos modelos de prestação como os hospitais-dia e a assistência domiciliar (homecare), por exemplo, haveria, até 2030, uma profunda reformulação da infraestrutura física instalada e da distribuição e qualificação dos profissionais de saúde. Assim, diversos serviços, atualmente prestados dentro de unidades de saúde, estariam mais desconcentrados no território brasileiro, movimento que ocasionaria diminuição do custo relativo de sua prestação ${ }^{21}$.

Barbosa (2009) ressalta o impacto desta reestruturação para potencializar redes integradas de serviços em saúde, com lógicas de integração verticais e horizontais, e com diferenciações internas, segundo tecnologias e demandas específicas, garantindo a efetividade e racionalidade da prestação dos cuidados.

Neste cenário mais otimista, o crescente papel do atendimento domiciliar e (ou) remoto poderia proporcionar importante expansão do acesso aos serviços em saúde. Ademais, a reestruturação física da prestação de cuidados em saúde ocasionaria uma maior dinamização nos processos inovativos no âmbito dos serviços médicos em ambientes outros que não essencialmente o hospitalar.

Entrevistados para a realização desta prospecção de cenário futuro, especialistas do Ministério da Saúde ressaltam que a intensificação do uso de tecnologia da informação também impactaria a natureza da interface entre os profissionais de saúde e a população. Dentre as consequências, haveria maior qualificação e atuação preventiva por parte da estratégia saúde da família e os agentes de saúde atenderão em visitas domiciliares, marcando uma atenção que consegue ser eficiente e individualizada ao mesmo tempo.

Ainda de acordo com os entrevistados, todos os segmentos da prestação de serviços seriam bastante dependentes de TIC, o que não somente facilitaria o acesso e promoveria maior individualização da atenção, como representaria importantes avanços na definição da porta de entrada no sistema de atenção, melhorando a eficácia do uso dos recursos da saúde.

21 O que não significa diminuição dos custos totais com a prestação de serviços em saúde. 
A tendência em 2030, de acordo com os especialistas, é que se tenha um atendimento bem mais individualizado e que o fluxo em direção aos centros de saúde e hospitais seja bastante reduzido e, sobretudo, mais organizado.

Tal reestruturação do formato de atenção à saúde afetaria também o perfil da infraestrutura hospitalar do futuro. Consequentemente, espera-se que haja importante alteração no porte dos hospitais, a exemplo daquela observada no âmbito dos países mais desenvolvidos.

De acordo com Barbosa (2009), até 2022 o segmento hospitalar brasileiro deverá dobrar o número médio de leitos por instituição em relação a 2005 (visando a um patamar de 120 por hospital). Entretanto, a perspectiva é de que se continue reduzindo o número de leitos per capita, que atualmente é de 2,3 leitos por mil habitantes ${ }^{22}$, para padrões inferiores a 1,5 leitos por mil habitantes. Esta previsão para 2022 reflete o enquadramento brasileiro nos padrões dos países que lideram as trajetórias tecnológicas deste subsistema (de serviços em saúde).

Vale ressaltar que a despeito desta tendência de redução de leitos per capita, é razoável considerar que a dimensão continental do Brasil sugere um número ótimo de leitos por mil habitantes superior àquele dos países mais desenvolvidos, de modo a atender não somente às necessidades de economia de escala do sistema hospitalar, mas também às de promoção do acesso.

A queda do número de leitos por mil habitantes, atualmente observada no Brasil, é explicada pela já referida dinâmica de concentração do mercado privado, em busca da realização de economias de escala. Esta queda não reflete, portanto, um planejamento e análise de custo-efetividade da infraestrutura hospitalar que o país precisa ter. Assim, observa-se uma redução do número de leitos hospitalares privados, concomitante a um aumento dos públicos, ainda que sem intensidade suficiente para compensar a redução no setor privado ${ }^{23}$.

Ressalte-se que para o planejamento do cenário futuro em relação ao tamanho do parque hospitalar deve-se considerar não somente a necessidade de buscar economias de escala que tornem viável o sistema, como também se deve evitar que esta concentração de leitos por hospital seja excessiva, o que dificultaria o acesso do serviço para a população (MCKEE e HEALLY, 2000).

De toda forma, em um cenário otimista, importa dizer que até 2030 observar-se-ia importante economia de escopo na atenção hospitalar e os grandes hospitais iriam se configurar como centros de excelência, o que contribuiria para o

22 Dados de 2009, atualizados de acordo com IBGE/ AMS 2009.

23 Uma das consequências deste movimento, na atualidade, é que as desigualdades de distribuição destes leitos em território nacional persistem. 
fortalecimento da sua atuação na formação de especialistas e de educação permanente e, possivelmente, no desenvolvimento de projetos de investigação clínica. Deste modo, o ambiente hospitalar permaneceria como importante protagonista na geração de inovação em saúde.

A redefinição do escopo dos hospitais aponta que sua atuação, já em 2022, seja voltada para a atenção de alta complexidade e a agudização de situações crônicas. E que em 2030 suas funções, além da prestação de serviços, estejam estruturadas e atendendo à demanda do sistema como um todo.

Em resumo, a perspectiva é de que, em 2030, a integração da rede de atenção poderia se efetivar facilitada pela introdução de novas tecnologias que permitem variações no formato da prestação de cuidados, fazendo surgir novas modalidades de assistências (hospital-dia, cirurgias ambulatoriais, assistência domiciliar, diagnóstico remoto, etc) e novos tipos de serviços, como a atenção domiciliar, configurando um sistema de atenção mais individualizado.

A alteração no escopo hospitalar, o adensamento tecnológico extrahospitalar, e a mudança do formato da prestação dos serviços contribuiriam para efetivar o movimento de migração da porta de entrada para a atenção primária. Este movimento é hoje observado no cerne da reestruturação dos sistemas de serviços em saúde, tanto no Brasil quanto no mundo. Os hospitais tenderiam a ser tecnologicamente mais densos, o que permite afirmar que, mesmo não mais no centro de atenção do sistema, continuariam responsáveis, em 2030, pela utilização de parcela importante dos recursos da atenção à saúde, ainda que os recursos sejam gastos de forma mais eficaz.

Tal reestruturação - que engloba atendimento em casa, incorporação de tecnologias que demandam menos tempo de internação hospitalar, entre outros - possibilitaria a multiplicação dos pontos de acesso de interação qualificada entre o sistema e o paciente, em especial nas regiões mais remotas, com consequências para a prestação e para a geração de inovação.

Entretanto, ela não beneficiaria, com a mesma intensidade, pessoas e lugares mais pobres, sem infraestrutura mínima para iniciar e (ou) continuar o cuidado especializado fora do ambiente hospitalar ou análogo. Fato este que deve ser considerado no planejamento atual da reestruturação do SUS, para consolidar de fato um modelo mais inclusivo de atenção.

Note-se que estas desigualdades observadas na prestação dos serviços em saúde, de caráter tanto de renda quanto regional, conforme se argumentou neste estudo, engloba variáveis relativas à necessidade de se reformar o Estado Brasileiro, que hoje também se traduz em limites ao financiamento da saúde (incompatíveis com o SUS do presente e do futuro), nos modelos de gestão da saúde (atualmente extremamente burocráticos e engessados), e na própria fragilidade estrutural do contexto federativo democrático brasileiro. 
Sem uma reforma política que contemple a superação de obstáculos macropolíticos diversos, sem a efetivação da coordenação da atuação das três esferas de governo, e sem a recuperação do papel dos governos estaduais, dificilmente poderse-á enfrentar as lacunas que impedem a saúde brasileira de se universalizar em toda a extensão do território nacional. Além disto, ficará inviabilizada a estruturação e integração das redes de serviços de saúde. Logo, a adequação das relações federativas nacionais, e seu impacto na saúde, além das demais questões detalhadas, condicionam também a possibilidade de que, em 2030, este seja um sistema mais equânime, integral e universal de saúde.

Além disto, vale ressaltar que a efetiva integração dos serviços em saúde pressupõe a organização e coordenação dos atores públicos e privados envolvidos na prestação dos serviços de saúde, suscitando a necessidade de se refletir sobre que papel deve desempenhar o sistema privado e sobre a continuidade de subsídios públicos para a atuação privada (que beneficia tão somente parcela reduzida e privilegiada da população). O enfrentamento de tais questões representa alto custo político, e, decorrente disto, ainda não é realizado de forma sistemática.

A definição de como o Estado vai regular a atuação deste segmento, além de seu sucesso em contornar as distorções de seu financiamento, implicam cenários futuros distintos referentes ao alcance dos princípios do SUS. Em função disto, é oportuno ressaltar a importância de se considerar as tendências do mercado de saúde suplementar para se pensar cenários futuros dos serviços em saúde.

De acordo com Barbosa, em análise realizada em 2009 acerca da dinâmica de investimentos dos serviços em saúde, no processo de reestruturação do mercado de saúde suplementar, continuará a redução, já em curso, do número de operadoras de planos de saúde (com fechamentos ou incorporações em ritmo superior a 10\% a.a.) ${ }^{24}$.

Como consequência do acirramento da competitividade neste nicho, hospitais e leitos, assim como serviços de diagnose privados, tenderiam a ser bastante reduzidos. Seguiria, de acordo com o autor, a tendência à oligopolização deste mercado e, em decorrência, menos de dez grupos reuniriam mais da metade da prestação de serviços intra-hospitalares, no ano de 2012. Barbosa (2009) aponta ainda a tendência de verticalização (envolvendo operadoras de planos, hospitais e serviços de diagnose) e associação deste segmento com a indústria de equipamentos e reagentes para diagnóstico.

A previsão é que se acirrem movimentos atuais que já refletem as tendências de concentração no mercado, a exemplo da recente compra do controle do hospital São Luiz por parte do banco BTG Pactual — por meio da Rede D'Or. Com essa

24 De acordo com dados da ANS (2012), de 2003 para 2012, o número de operadoras médico-hospitalares em atividade no Brasil passou de 1345 para 973. 
operação, a carioca D'Or consolida ainda mais sua posição de maior grupo hospitalar do país, com faturamento de $\mathrm{R} \$ 2,3$ bilhões.

Outro exemplo é a incorporação da holding de laboratórios MD1 Diagnósticos, controlada por Edson Godoy Bueno, maior acionista da Amil, pela Dasa. A empresa cresce significativamente com a transação e se torna líder de mercado no Rio, onde os laboratórios da MD1 possuem presença relevante. Analistas apontam que, para este negócio, a complementaridade das empresas foi fundamental.

De forma análoga, o Fleury, principal concorrente da rede de laboratórios, que não possuía a presença nacional da Dasa e tem entre os acionistas o Bradesco, que concorre com a Amil no segmento de planos de saúde ${ }^{25}$, amplia suas participações com a aquisição da rede de laboratórios Cardiolab, do grupo Labs D’Or. É válido ressaltar que a Amil fez uma aquisição da Medial no final de 2009, o que ilustra claramente os processos de concentração e diversificação descritos anteriormente ${ }^{26}$.

Dada a importância do segmento privado da prestação de serviços em saúde, é fundamental sublinhar que a integração e subordinação do mercado privado ao público só ocorrerá se houver significativo aumento da participação pública no financiamento à saúde. Este aumento da participação pública tem particular relevância devido a mudanças que pressionarão o sistema de saúde como o desempenho socioeconômico observado na última década no Brasil, o crescimento do mercado formal de trabalho e seu impacto sobre a dinamização da prestação privada de atenção à saúde; e, especialmente, ao se considerar que as previsões quanto à continuidade do crescimento socioeconômico brasileiro são favoráveis.

Assim, chama-se atenção para um importante desafio para a efetividade do SUS no futuro: a capacidade de majorar o financiamento público da saúde e a definição de como fazer o sistema privado reembolsar o SUS efetivamente quando seus clientes utilizarem a rede pública são variáveis que devem ser equacionadas para se alcançar a integração efetiva da rede de saúde e sua reestruturação de acordo com as demandas coletivas.

No SUS, a aposta pelo aporte de recursos compatível com seu modelo político institucional guarda sinonímia com a sustentabilidade deste sistema de saúde e com sua capacidade de responder aos desafios futuros. Previsão realizada por Barbosa (2009) aponta que, para alcançar a universalização e a integralidade, os gastos em saúde deveriam ser, até 2022, da ordem de 11\% do PIB e que a participação do segmento público, neste financiamento, deveria chegar ao menos ao patamar de 70\%, participação compatível com a dos países mais desenvolvidos.

25 Valor Econômico, 01/09/2010.

26 Em meados de 2012 a AMIL foi adquirida pela empresa norte americana United Health, líder no segmento da saúde suplementar nos Estados Unidos. Ainda que tal transação não tenha afetado a concentração do mercado nacional, indica um possível acirramento da competição do mercado de serviços de saúde no Brasil. 
Ainda que a necessidade de expandir o financiamento da saúde não seja objeto de disputa, há de se avaliar a real possibilidade de que em 2030 os gastos em saúde cheguem ao patamar desejável, em torno de 12 a 15\% do PIB, com a participação pública no patamar de pelo menos $70 \%$ do total. ${ }^{27}$ Deste modo, importa aqui afirmar que, com o advento da expansão prevista dos custos da saúde em 2030 e o envelhecimento da população, a não revisão da base de financiamento do SUS significaria a revisão velada de seus princípios.

Outra questão crítica para o desempenho futuro do SUS refere-se à fragilidade da sua base de conhecimento, que pauta, já na atualidade, importante vulnerabilidade para o sistema de saúde brasileiro, uma vez que pontua a dependência da saúde à capacidade de produção e interesses internacionais de naturezas diversas. Sem contar que esta vulnerabilidade diminui o protagonismo das necessidades de saúde da população brasileira na priorização do desenvolvimento de C\&T e no surgimento de novas tecnologias para a saúde.

A debilidade da produtividade e competitividade do complexo da saúde brasileiro tem ocasionado crescente déficit na balança comercial da saúde. Ademais, a proliferação de tecnologias e a inadequação de critérios de incorporação tecnológica têm contribuído para a participação cada vez maior dos equipamentos médicos e insumos nos gastos em saúde, sem necessariamente apresentar custo-efetividade coerente com as diretrizes do SUS.

Em 2030, o país teria uma estrutura de avaliação tecnológica madura, dado que seriam desenvolvidas redes, centros de avaliação de tecnologia e afins para apoiar o Estado a subsidiar a incorporação tecnológica, quesito fundamental para garantir a sustentabilidade do SUS. Este processo de definição acerca de o que deveria ou não ser incorporado pelo SUS envolve: o reconhecimento de que o sistema de saúde brasileiro é peculiar no que tange ao porte do segmento de saúde suplementar; o decorrente questionamento de qual deve ser o papel do segmento privado na universalização do acesso, além de; a definição de qual sistema de saúde quer a sociedade brasileira.

O Complexo da saúde ainda não será autossuficiente em 2030, mas observar-se-ão importantes avanços na adequação do arcabouço político institucional do CEIS, permitindo que crescentemente haja articulação sistêmica entre as demandas da saúde e a geração e incorporação tecnológica para a saúde. Em decorrência, a judicialização da saúde, mesmo que ainda presente, não sequestraria recursos

27 A despeito do consenso de que o subfinanciamento representa importante entrave ao SUS, a falta de apoio político ao mesmo parece fazer com que esta realidade não se altere de forma significativa. Na última década acreditou-se que a regulamentação da Emenda Constitucional 29 representaria um passo significativo na reversão deste cenário. Entretanto, a observação de que demorou mais de uma década para regulamentá-la, de que neste ínterim foi extinta a CPMF, de que o impacto da EC 29 é insuficiente para lidar com os desafios postos pelo subfinanciamento da saúde e, por fim, o fato de que não se discute de forma sistemática fontes alternativas de financiamento à saúde apontam para a falta de apoio político referida. 
orçamentários de entes federados a ponto de ameaçar a sustentabilidade financeira de suas demais ações de saúde no ano de 2030.

Por fim, vale enfatizar que a recuperação da centralidade do Estado na agenda de desenvolvimento nacional deverá levar ao crescente fomento à cultura de inovação no país, o que beneficiará a base produtiva do Complexo. Entretanto, resta a questão sobre qual modelo de desenvolvimento será engendrado no período até 2030. Ainda que não se questione que a inovação será protagonista do mesmo, resta saber se os interesses coletivos nortearão a escolha das trajetórias tecnológicas das políticas de fomento à inovação. Esta questão configurará importante diferencial na história de desenvolvimento do Brasil, assim como definirá o protagonismo dos interesses sociais junto aos segmentos industriais da saúde.

O enfrentamento das dicotomias entre os interesses públicos e privados e a superação de um olhar enviesado desta relação, assim como a definição do modelo de atenção à saúde que se quer de fato no Brasil (e o quanto a sociedade se dispõe a pagar por ele) são variáveis determinantes da dinâmica dos serviços em saúde em cenário futuro.

Assim, muitas questões políticas precisam ser definidas para que se preveja o SUS que o país terá. Se a sociedade brasileira buscar de fato a consolidação do modelo de proteção social proposto na Constituição Federal, reafirmado nas lutas setoriais, então o cenário observado em 2030 deverá contar com o aumento substancial do financiamento em saúde, o fortalecimento da base produtiva do CEIS, a integração de redes de saúde e o fortalecimento da coordenação federativa. De forma análoga, a não superação dos entraves políticos do SUS ocasionará um sistema de saúde insustentável e inconsistente com o modelo político e institucional proposto pelo movimento sanitarista e reafirmado em 1988.

\section{5 | CONSIDERAÇÕES FINAIS}

A prestação universal dos serviços em saúde no Brasil foi garantida em 1988 na Carta Constitucional, na qual a saúde foi estabelecida como um direito do cidadão e dever do Estado. A despeito das dificuldades encontradas, da crise fiscal subsequente, e da corrente neoliberal hegemônica até a década de 2000, marcada pela orientação para a diminuição do papel do Estado e redução de gastos públicos, muitos êxitos foram logrados, conforme demonstram os principais marcadores em saúde.

$\mathrm{Na}$ atualidade, a promessa de melhoria na qualidade no atendimento e na condição de saúde da população, de expansão no acesso e do aumento da expectativa de vida, decorrente da evolução das condições socioeconômicas da população e de inovações tecnológicas em saúde, vem resultando não somente na 
expansão da demanda como no aumento dos custos agregados da saúde. A tendência é de continuidade e acirramento deste cenário, o que enfatiza a necessidade de realizar reformas no interior do sistema nacional de saúde e de reformular o modelo de atenção à saúde no Brasil.

As orientações macropolíticas, setoriais e extrassetoriais, e o modelo institucional do SUS, uma vez colocados em prática, permitem inferir que em 2030 haveria uma total reestruturação do modelo de prestação de serviços em saúde e do próprio sistema de saúde brasileiro. Esta seria marcada pela busca e alcance da integração (vertical e horizontal da atenção) da rede de serviços, e por uma aproximação dos canais e locais de prestação de cuidados aos pacientes. Novos formatos de prestação dos serviços em saúde seriam possíveis inclusive graças a uma gama diversa de tecnologias incorporadas, voltadas à necessária reestruturação do sistema como um todo.

Prontuários eletrônicos, equipamentos móveis, kits de diagnósticos, entre outros, além de novas soluções que surgirão, seriam, neste cenário, amplamente utilizados. Ademais, observar-se-ia a individualização do tratamento, implicando na clara necessidade de que o sistema de saúde tenha uma infraestrutura de TIC robusta, e um qualificado sistema de informações.

O sistema de saúde brasileiro ampliaria seu foco para um cuidado preventivo e de caráter continuado, além de aprimorar a atenção intensiva. Assim, além de uma maior especialização dos hospitais e clínicas ambulatoriais, novos atores, inclusive os próprios pacientes e seus familiares, serão mais atuantes na prestação do cuidado. Isto decorreria da aceleração e intensificação dos processos de mudança dos locais tradicionais para o tratamento.

Além disto, a prestação dos serviços atuaria mais ativamente no controle de doenças, ao fazer uso de abordagens padronizadas a condições individuais, possíveis graças à farmacogenômica, à metabolômica, à medicina regenerativa, entre outros, conforme afirmaram especialistas entrevistados do Ministério da Saúde. O cuidado estaria mais baseado em evidências e padronizado, e haverá estruturas múltiplas de serviços, que estarão alinhadas e integradas (IBM, 2006).

Uma nova composição de financiamento da saúde, condizente com o modelo de Bem Estar preconizado na Constituição, permitiria avançar na integração de redes de saúde, com ampla utilização de tecnologias de informação e comunicação, individualização e especialização da atenção e organização dos fluxos de atenção, que pressupõe evolução na coordenação federativa nacional. O modelo seria pactuado e coordenado entre as três esferas de governo, com clara definição do papel do setor privado e do público, permitindo avançar na universalização e integralização de um acesso mais equitativo ao longo do território nacional. 
Ressalta-se, assim, que a incorporação dessas tecnologias e as transformações que elas têm causado no âmbito dos sistemas de saúde seguiriam ao encontro da necessidade de expandir o acesso e reduzir os custos da atenção, com enfoque na prevenção e integração da atenção. E devem contribuir, sobremaneira, para a efetivação da integração das redes de saúde até 2030.

Este é um cenário possível, e, ademais, compatível com as demandas do futuro e com o modelo político institucional do SUS. Baseia-se, portanto, naquilo por que se lutou e que se institucionalizou a partir do movimento sanitarista. Ou seja, este cenário alvissareiro baseia-se na concretização de conquistas quanto ao modelo de bem estar social e fundamenta-se nas prioridades institucionalizadas pelo governo federal quanto à escolha da trajetória de desenvolvimento nacional. Pressupõe, ademais, que o país fortaleça sua capacidade de geração, uso e difusão de inovação e que o modelo de desenvolvimento seja socialmente inclusivo, ou seja, que as inovações orientem-se pelo perfil de demanda social. Este cenário configura-se com um grau de otimismo exacerbado, considerando-se as ultimas duas décadas de falta de apoio sistemático ao SUS e as dificuldades de se estabelecer um pacto federativo em um país com o porte e complexidade do Brasil.

Há, na realidade, barreiras diversas para se alcançar este futuro, e elas são essencialmente de cunho político.

Dada a proximidade do campo da saúde ao do desenvolvimento, podese depreender que a superação de tais barreiras no futuro em análise pode se resumir direta e intrinsecamente ao modelo de desenvolvimento implementado no país, para além da retórica estabelecida nos documentos políticos. Vale enfatizar ainda que, na revisão dos interesses públicos e privados da saúde, cabe maior protagonismo dos serviços de saúde na orientação da base produtiva e inovativa do CEIS; sendo este o principal desafio do segmento de serviços em saúde: o de protagonizar a orientação destas inovações que devem ser incorporadas somente quando atenderem os preceitos e princípios do SUS. Somente assim, em 2030, o Sistema Nacional de Inovação em Saúde poderá de fato incorporar as necessidades coletivas de saúde, e por elas se orientar.

Em resumo, caso o governo brasileiro seja bem sucedido em engendrar um padrão de desenvolvimento inclusivo, em que as inovações atendam aos interesses sociais, há ainda a necessidade de fortalecimento da atuação do Estado brasileiro, em especial no que diz respeito à necessidade de consolidar seu papel de mediador, garantido pelo fortalecimento do arcabouço regulatório nacional. Deve ser capaz de garantir o custo efetividade das tecnologias assistenciais incorporadas e, de forma mais geral, o Estado precisa atuar na orientação e regulação do estabelecimento de uma relação virtuosa entre os interesses econômicos e sociais, constantemente tensionados no âmbito das políticas e sistemas de saúde. 
Ressalte-se ainda o papel do Estado no fortalecimento do Sistema Nacional de Inovação em Saúde e seu complexo produtivo, visando reverter a dependência externa em setores-chave para a política de saúde e para o desenvolvimento nacional. Com este intuito, deverá promover a qualificação dos recursos humanos com olhar intersetorial, e orientar a produção de tecnologias capazes de aliar as necessidades sociais e oportunidades econômicas para o desenvolvimento do CEIS.

Além disto, o debate sobre o financiamento da saúde tem que superar seu insulamento, pois o alcance deste cenário otimista também é condicionado à expansão substancial do financiamento da saúde, em especial dos recursos de origem pública, sem o que não haverá condições de reversão de sérias fragmentações e desigualdades de renda e regionais observadas. Ou seja, reafirma-se a necessidade de alterar a composição do financiamento em saúde, que atualmente é majoritariamente privada, de modo a torná-lo compatível com um sistema universal de saúde.

Além do financiamento, o Estado precisa também aprimorar a gestão do sistema de saúde, o que remete à urgência de se promover, efetivamente, a integração da rede de atenção à saúde. Trata-se, dentre outras questões, da necessidade de aprimorar seus modelos de gestão, coibir descontinuidades administrativas, estruturar um sistema regionalizado e hierarquizado, cuja organização consiga contemplar seus atores privados e os públicos. Neste sentido, há que se qualificar a coordenação federativa e recuperar o papel dos estados.

Vale enfatizar que os avanços observados até o momento, decorrentes da recente centralidade da saúde na agenda de desenvolvimento, ainda apontam para um descompasso entre a conformação de um sistema universal e o processo de consolidação do SUS, uma vez que o mesmo depara-se com importantes lacunas para o seu desenvolvimento. Em suma, ainda não se conseguiu estabelecer uma agenda virtuosa entre saúde e desenvolvimento, e permanecem dicotômicos interesses que poderiam se complementar. A mera continuidade das políticas atuais, sem engendrar reformas mais substantivas na estrutura do estado, apontaria para um caráter utópico de um cenário otimista, como o supra desenhado. 


\section{6 | REFERÊNCIAS BIBLIOGRÁFICAS}

ALBUQUERQUE, EM. Celso Furtado, a polaridade modernização-marginalização e uma agenda para a construção dos sistemas de inovação e de bem-estar social. In: Saboia, J, Carvalho, FJC (orgs). Celso Furtado e o século XXI. Barueri, SP: Manole; Rio de Janeiro: Instituto de Economia da Universidade Federal do Rio de Janeiro, 2007.p. 181 - 203.

ALBUQUERQUE, EM E CASSIOLATO, JE. As especificidades do sistema de inovação do setor saúde: uma resenha da literatura como introdução a uma discussão sobre o caso brasileiro. Belo Horizonte: Fesbe; 2000.

BARBOSA, PR. Documento Setorial: Serviços em Saúde. In: Gadelha, CAG (coord). Perspectivas do investimento no Brasil. Bloco: Economia do conhecimento. Sistema produtivo: Complexo Industrial da saúde. IE - UFRJ/ IE-Unicamp - BNDES. Rio de Janeiro, 2009. Disponível em: <http://www.projetopib.org/?p=documentos $>$. Acesso em julho de 2011.

BIRD. Envelhecendo em um Brasil mais velho: implicações do envelhecimento populacional para o crescimento econômico, a redução da pobreza, as finanças públicas e a prestação de serviços. Sumário. Banco Mundial, Brasil, 2011.

BOYLE, D. O Manifesto Comunista de Marx e Engels. Rio de Janeiro: Jorge Zahar Ed., 2006.

BRASIL. MINISTÉRIO DA SAÚDE. AGÊNCIA NACIONAL DE SAÚDE (ANS). Sistema de Informações de Beneficiários. Agência Nacional de Saúde. Disponível em: <http://www.ans.gov.br/>. Acesso em fevereiro de 2013.

BRASIL. MINISTÉRIO DA SAÚDE. Mais saúde: direito de todos: 2008 - 2011. Ministério da Saúde, Secretaria-Executiva. 2a . ed. - Brasília, DF: Editora do Ministério da Saúde, 2008. Disponível em: <http://bvsms.saude.gov.br/bvs/publicacoes/mais_saude_direito_todos_2ed. pdf $>$. Acesso em julho de 2011.

BRASIL. MINISTÉRIO DA SAÚDE. Sala de situação em saúde. Ministério da Saúde, 2011. Disponível em: <http://189.28.128.178/sage/ > . Acesso em julho de 2011.

CAETANO, R. Paradigmas e trajetórias do processo de Inovação tecnológica em Saúde. PHYSIS: Saúde Coletiva, Rio de Janeiro, 1998. 8(2): (p. 71 - 94).

COSTA, LS, et al. A Dinâmica Inovativa para a Reestruturação dos Serviços de Saúde. Revista de Saúde Pública da USP. Suplemento Especial Saúde e Desenvolvimento. São Paulo, 2012.

DJELLAL, F. e GALLOUJ, F. Innovation in hospitals: a survey of the literature. Eu J Health Econ (2007) 8:181 - 193.

DOSI, G. The nature of the innovative process. In: Dosi, G. Et al, editors. Technical change and economic theory. London; Pinter Publishers, 1988 (p. 221-38)

FAVERET, P e OLIVEIRA, PJ. A universalização excludente: reflexões sobre as tendências do sistema de saúde. In: Planejamento e Políticas Públicas, nº 3, p.139-162, IPEA, 1990.

FIORI, JL. O federalismo diante do desafio da globalização. IN Affonso, RBA e Silva, PLB (orgs). A federação em perspectiva. São Paulo: FUNDAP, 1995, p.19-38.

GADELHA, CAG \& COSTA, LS. Trajetória Brasil 2003-2009. A Saúde na Perspectiva da Proposta de Desenvolvimento do Governo Federal. Nota Técnica. Brasília: CGEE, 2010. 
GADELHA, CAG. O complexo industrial da saúde e a necessidade de um enfoque dinâmico na economia da saúde. Ciência e Saúde Coletiva, 8(2): 521-535, Rio de Janeiro, 2003.

GADELHA, CAG e COSTA, LS. Saúde e desenvolvimento Nacional: a gestão federal entre 2003 e 2010. In: MACHADO, CV; BAPTISTA, TWF e LIMA, LD (Org). Política de saúde no Brasil: continuidades e mudanças. Rio de Janeiro: FIOCRUZ, 2012.

GADELHA, CAG e COSTA, LS. Saúde e desenvolvimento. In: FUNDAÇÃO OSWALDO CRUZ, et al. A saúde no Brasil em 2030: diretrizes para a prospecção estratégica do sistema de saúde brasileiro. Rio de Janeiro: Fiocruz, 2013.

GADELHA, CAG, et al. Boletim Informativo do Grupo de Pesquisa de Inovação em Saúde da ENSP/VPPIS/Fiocruz/MS - Informe CEIS n 1, ano 1 - Agosto 2010.

GADELHA, CAG. MALDONADO, JMSV, VARGAS, M E BARBOSA, PR. Sistema produtivo: Complexo Industrial da saúde. In: Gadelha (coord.), Relatório Final do Projeto Perspectiva de Investimento no Brasil. IE-UFRJ / IE-Unicamp-BNDES. Rio de Janeiro, 2009a. < http://www.projetopib. org/?p=documentos $>$. Acesso em julho de 2011.

GADELHA, CAG; et al. A dinâmica do sistema produtivo da saúde: inovação e complexo econômico-industrial. Rio de Janeiro: Ed. Fiocruz, 2012; 221p.

GADELHA; CAG; MACHADO, CV; LIMA, LD; \& BAPTISTA, TWF. Saúde e Desenvolvimento: uma perspectiva territorial. In: D'AVILA VIANA, AL, IBAÑEZ, N; e ELIAS, PEM - Saúde, Desenvolvimento e Território. Hucitec: São Paulo, 2009b.

GLOBAL FORUM FOR HEALTH RESEARCH. Monitoring Financial Flow for Health Research: the changing landscape of health research for development. Geneva: Andrés de Francisco and Stephen Matlin (ed.), 2008.

IBAÑEZ, N. Análise comparada de Sistemas de Saúde. In IBAÑEZ, N, ELIAS, PEM, SEIXAS, PHD (org). Política e Gestão Pública em Saúde. São Paulo: Hucitec: Cealag, 2011.

IBM. A Saúde em 2015: "Ganha-Ganha" ou "Todos Perdem"? Um retrato e um caminho para uma transformação de sucesso. 2006. Disponível em: < http://www.ibm.com/expressadvantage/ br/downloads/saude_2015_todos_perdem.pdf. > Acesso em novembro de 2010.

LA FORGIA, GM e COUTTOLENC, BF. Desempenho hospitalar no Brasil: em busca de excelência. Editora Singular: São Paulo, 2009.

LOBATO, LVC e GIOVANELLA, L. Sistemas de Saúde: origens, componentes e dinâmica. In: GIOVANELLA, L.; LOBATO, L.; ESCOREL, S. \& NORONHA, J. (Orgs.). Políticas e Sistemas de Saúde no Brasil. Rio de Janeiro: Ed. Fiocruz, 2008.

MACHADO, CV \& VIANA, AL. Descentralização e coordenação federativa na saúde. In: VIANA, AL, IBAÑEZ, N, ELIAS, PEM (orgs). Saúde, Desenvolvimento e Território. São Paulo, 2009. Editora Hucitec; 2009. Pags 21 a 59.

MCKEE, M.; HEALY, J. The role of the hospital in a changing environment. Bulletin of the World Health Organization, Geneva, v. 78, n. 6, p. 803-810, 2000.

MENICUCCI, T. A implementação da Reforma Sanitária: a formação de uma política. In HOCHMAN, G, ARRETCHE, M e MARQUES, E (orgs). Políticas públicas no Brasil. Rio de Janeiro, Ed. Fiocruz, 2007.

NORONHA, JC. Financiamento setorial e dilemas para o futuro. Apresentação cedida pelo autor, 2011. 
OLIVEIRA, T. Cenário sociodemográfico em 2022/2030 e distribuição territorial da população: uso e ocupação do solo. In: FUNDAÇÃO OSWALDO CRUZ, et al. A saúde no Brasil em 2030: diretrizes para a prospecção estratégica do sistema de saúde brasileiro. Rio de Janeiro: Fiocruz, 2013.

PAHO. Cuidados Inovadores para Condições Crônicas: componentes estruturais de Ação: Relatório Mundial/OMS - Brasília, 2003.

PAIM, J; TRAVASSOS, C; ALMEIDA, C; BAHIA, L; MACINKO, J (2011). Saúde no Brasil 1: O sistema de saúde brasileiro: história, avanços e desafios. The Lancet, Volume 377, Issue 9779, Pages 1131, 9 May 2011.

PIERSON, P. Increasing Returns, Path Dependence, and the Study of Politics. American Political Science Review, Volume 94, Numero 2, June 2000.

PIOLA, SF e VIANNA, SM (org.). Estado de uma nação: textos de apoio. Saúde no Brasil: algumas questões sobre o sistema único de saúde (SUS). Texto para discussão no 1391, IPEA. Produzido no programa de trabalho de 2008, Brasília, fevereiro de 2009.

UGÁ, MAD e MARQUES, RM. O Financiamento do SUS: trajetória, contexto e constrangimentos. In: LIMA, NT, GERSCHMAN, S e EDLER, FC (orgs). Saúde e Democracia: história e perspectivas do SUS. Rio de janeiro, Editora Fiocruz, 2005 (pags. 193-233).

VALOR. Análise setorial: Hospitais Privados. Estudos setoriais, 2008.

VIACAVA, F, et al. Uma metodologia de avaliação do desempenho do sistema de saúde brasileiro. Ciência e Saúde Coletiva, 9 (3): 711-724, 2004.

VIANA, ALD e MACHADO, CV. Proteção social em saúde: um balanço dos 20 anos do SUS. Physis Revista de Saúde Coletiva, Rio de janeiro, 18 [4]: 645-684, 2008.

VIANA, ALD, e ELIAS PEM. Economia política da saúde: introduzindo o debate. Divulg. Saúde Debate. 2007 p. 7 - 20.

VIANA, ALD, NUNES, AA e SILVA, HP. Complexo Produtivo da Saúde, desenvolvimento e incorporação de tecnologias. In IBAÑEZ, N, ELIAS, PEM, SEIXAS, PHd'A (org). Política e Gestão Pública em Saúde. São Paulo: Hucitec: Cealag, 2011.

VIANNA CMM. Política tecnológica e evolução industrial no setor da saúde. In: Guimarães R, Tavares RAW. Saúde e sociedade no Brasil: anos 80. Rio de Janeiro: Relume Dumará; 1994. p. 209-52.

VICTORA, CG, et al. THE LANCET BRAZIL SERIES WORKING GROUP. Saúde no Brasil 6: Condições de saúde e inovações nas políticas de saúde no Brasil: o caminho a percorrer. The Lancet, Volume 377, Issue 9782, Pages 90-102, 9 May 2011.

VIDOTTI, CCF; CASTRO, LLC e CALIL, SS. New drugs in Brazil: do they meet Brazilian public health needs? In: Rev Panam Salud Publica / Pan Am J Public Health 24 (1), 2008 (p. 36-45).

WORLD HEALTH ORGANIZATION (WHO). Medical Devices: Managing the Mismatch: an Outcome of the Priority Medical Devices Project. World Health Organization, 2010.

WORLD HEALTH ORGANIZATION (WHO). Dados disponíveis em http://apps.who.int/gho/data/ view.main.1901. Acesso em: fev. de 2013. 